\title{
UN “CANTAR DE GESTA” INCA EN UN QUERO COLONIAL: PRESENTACIÓN Y ESTUDIO PRELIMINAR
}

\author{
AN INCA “EPIC HYMN” IN A COLONIAL QUERO: PRESENTATION AND \\ PRELIMINARY STUDY
}

\author{
Mariusz Ziótkowski ${ }^{1}$ y Sylwia Siemianowska ${ }^{1,2}$
}

\begin{abstract}
La existencia de una tradición inca de representaciones pictóricas de carácter narrativo, con función de registros históricos, está confirmada tanto por un grupo de obras de arte, muy probablemente de orígen prehispánico, como por fuentes escritas. La referencia más conocida sobre "pinturas históricas" de los incas es, sin duda, la relativa a las famosas "tablas de Poquen Cancha" hoy desaparecidas, pero que existieron y fueron consultadas hasta por lo menos mediados de los años 1560 . Se ha postulado, que estas "pinturas históricas" pudieron haber sido, en parte, copiadas durante el periodo Colonial en diferentes tipos de soportes, como lienzos y queros. En el presente texto se analiza la escena de un conflicto armado, representada en un quero, excepcional en cuanto a su complejidad y riqueza de detalles. Se avanza en la hipótesis de que pueda ser la representación del conflicto entre los Incas y los Chancas.
\end{abstract}

Palabras claves: Incas, Chancas, quero, arte prehispánico.

The existence of an Inca tradition of narrative pictorial representations, acting as historical records, has been substantiated by both a group of works of art, very probably of pre-Hispanic origin, and written sources. Clearly, the best known reference to "historical paintings" of the Incas is that regarding the famous, today dissapeared "tables of Poquen Cancha," which existed and were consulted until mid-1560s at least. It has been postulated that, during the Colonial period, part of these "historical paintings" may have been copied on different types of media, such as canvases and queros. In this article, the authors analyze the scene of an armed conflict represented in a quero, unusual in terms of its complexity and richness of detail, and put forth the hypothesis that it may be the representation of the conflict between the Incas and the Chancas.

Key words: Incas, Chancas, quero, pre-Hispanic art.

En la colección del Museo Etnográfico de Hamburgo (Alemania) ${ }^{1}$ se encuentra un quero colonial (objeto no. 61.38.1) con una representación bélica muy compleja e interesante (Figura 1, Anexo 1). El objeto tiene una altura de $21 \mathrm{~cm}$, con un diámetro de la boca de $18 \mathrm{~cm}$, y su decoración pictórica está realizada en técnica de laca incrustada. La decoración está relativamente bien conservada, salvo la parte inferior del objeto donde se nota la ausencia parcial, y en algunos casos total, de la laca, quedando solo la incisión. Fue adquirido por el Museo en 1961 de manos de un coleccionista privado, la procedencia exacta del vaso permanece desconocida ${ }^{2}$.

\section{La Escena Representada ${ }^{3}$}

El objetivo del presente estudio es un análisis preliminar de la escena reproducida. Esta comprende solo representaciones figurativas, no aparecen signos tocapus, caso frecuente en otros objetos de esta categoría. La escena representa un conflicto armado, con participación de 36 beligerantes. Es de señalar que todos lucen trajes personalizados, no hay dos personas idénticamente vestidas. No aparece ninguna representación de animal y tampoco de planta o cualquier rasgo ambiental, sin embargo, como se presentará a continuación, hay ciertos indicios que permiten ubicar al menos a algunos de los protagonistas en un contexto etno-geográfico más preciso.

\footnotetext{
${ }^{1}$ Centro de Estudios Andinos, Universidad de Varsovia, en el Cusco (CEACUV), Perú. mziolkowski@uw.edu.pl

${ }^{2}$ Instituto de Arqueología y Etnología de la Academia de Ciencias Polaca, Delegación en Wrocław, Polonia. sylwiasiemianowska@wp.pl
}

Recibido: septiembre 2019. Aceptado: febrero 2020.

http://dx.doi.org/10.4067/S0717-73562021005000404. Publicado en línea: 15-abril-2021. 

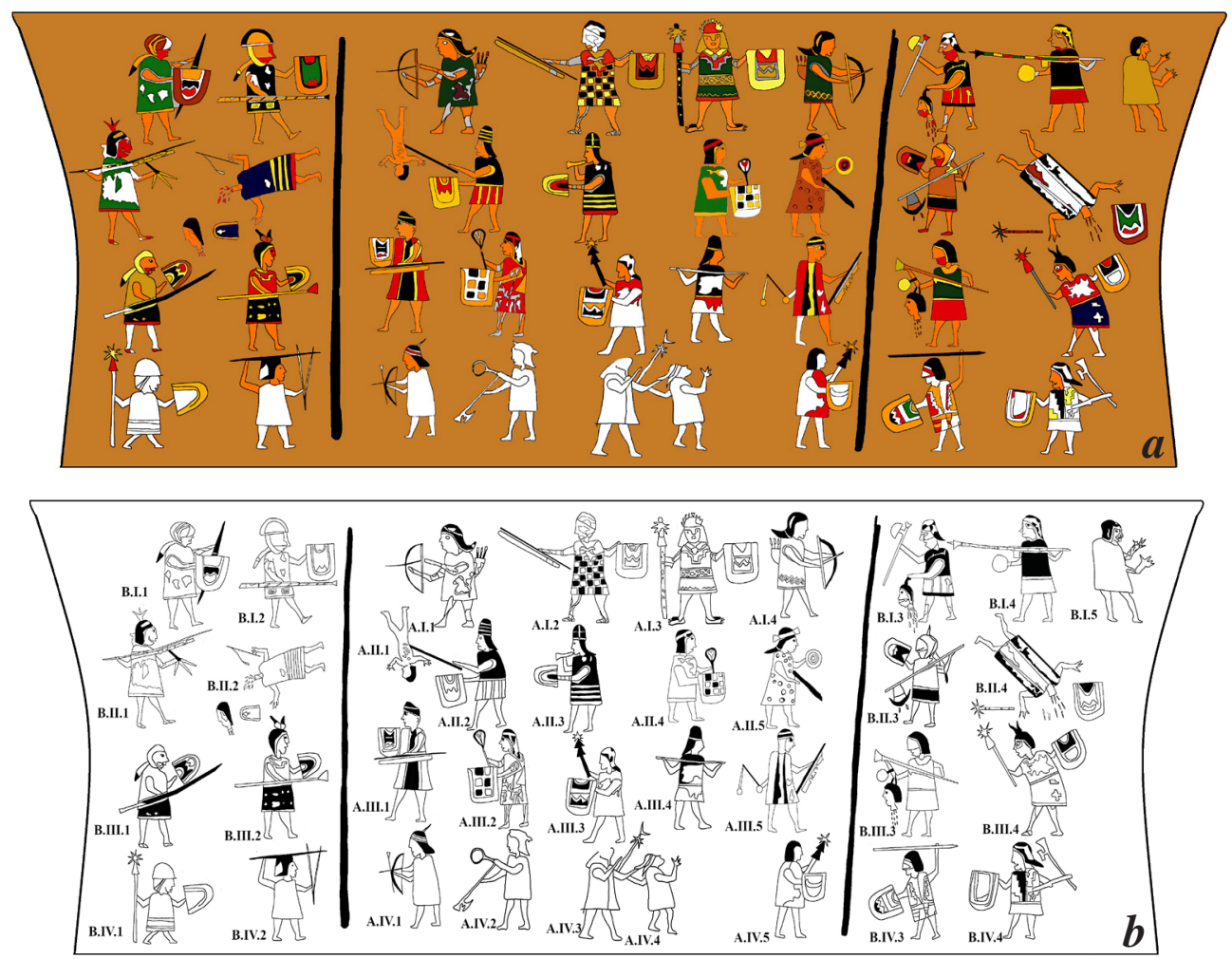

Figura 1. (a) Dibujo de la escena del quero no. 61.38.1 del MARKK (Hamburgo). Dibujo de Sylwia Siemianowska. Véanse las fotos del objeto (Anexo 1: fotos del q'ero de Hamburgo cortesía del Museum Am Rothenbaum. Kulturen und Künste der Welt, Hamburgo) y los dibujos detallados en Anexo 1. (b) Dibujo en blanco y negro con los códigos de los personajes representados en el Anexo 1.

(a) Drawing of the battle scene from the quero no. 61.38 .1 of the MARKK (Hamburg). Drawing by Sylwia Siemianowska. See photos of the object (Annex 1: photos courtesy of Museum Am Rothenbaum. Kulturen und Künste der Welt, Hamburg, and detailed drawings of the warriors in Annex 1). (b) Black and white drawing with the codes of the characters represented in Annex 1.

Las figuras forman cuatro hileras horizontales, y están repartidas en dos grupos claramente delimitados por dos líneas verticales de color negro, que van desde el borde del vaso hasta su pie (Figura 1).

\section{Grupo A}

Está constituido por 19 personajes. Un rasgo llamativo es la presencia en el registro superior de dos figuras que se pueden claramente identificar como miembros de la élite inca. Ambos llevan escudos conocidos de otros queros como identificadores de soberanos y/o militares de alto rango (Bielatowicz 2007; Ziółkowski 2009:fig.5:314). Tomando los escudos como principales distintivos, tentativamente podemos reconocer como incas a dos figuras más, pero en el grupo B (Figura 1, Anexo 1: B.IV.3, B.IV.4).

Aparte de los incas, a juzgar por la similitud de trajes y tipo de armas, se pueden diferenciar como mínimo cuatro otros subgrupos de guerreros:

- tres Antis (identificables por sus arcos), dos de estos en una ubicación prominente, en el registro superior, al lado de los incas (Figura 1 y Anexo 1: A.I.1, A.I.4, A.IV.1); que obviamente de alguna manera se unen con Antisuyu.
- dos Collas (a juzgar por el tipo de chucu o casco) en el segundo registro y probablemente uno más en el tercer registro (Anexo 1: A.II.1, A.II2, AIII4); esto a su vez es una referencia a Collasuyu.

Otros dos subgrupos, aunque claramente diferenciables, ya no son tan fáciles de identificar a nivel étnico:

- En la tercera hilera o fila, ambos personajes reproducidos cerca de las líneas divisorias verticales llevan el mismo tipo de uncu, tocados parecidos y el mismo tipo de arma (Anexo 1: A.III.1, A.III.5).

- Dos personajes de la segunda y tercera hilera caracterizados por el mismo tipo de escudo con un diseño similar a una tabla de ajedrez y el mismo tipo de armas (Anexo 1: A.II.4, A.III.1).

Cuatro personajes representados en la hilera inferior IV no se pueden identificar con certeza a causa del mal estado de conservación de la laca incrustada (Anexo 1: A.IV.1, A.IV.2, A.IV.3-4).

A diferencia del grupo B (ver más adelante), en el Grupo A no hay representaciones de personas claramente sacrificadas (decapitadas), pero sí posiblemente las de dos prisioneros:

- en el segundo registro (contando desde arriba) está representado un personaje desnudo yacente, apuntado 
con la lanza de un soldado, probablemente colla (Figura 1, Anexo 1: A.II.1-2).

- en el registro inferior, notamos la presencia de otro personaje, vestido y de pie, pero desarmado y agarrado por el cabello por un oponente. Esta es la típica referencia gráfica al acto de captura/sumisión (Anexo 1: A.IV.3-4).

- a diferencia de los guerreros representados en el grupo $\mathrm{B}$, ninguno de los integrantes del grupo A lleva pintura facial.

- solo en este grupo está representado un personaje tocando un tipo de trompeta; posiblemente una quepa o bocina elaborada con una calabaza (Anexo 1: A.II.3).

\section{Grupo B}

Está constituido por representaciones de 17 personajes, entre estos dos (o hasta tres) victimados: sus cuerpos decapitados yacen en el suelo.

La explicación de esta última situación es algo complicada y se resume en la siguiente pregunta: ¿quién ha matado a las víctimas? Si aceptamos la hipótesis de que el conflicto armado opone a los integrantes del Grupo A con los del Grupo B, lógicamente los responsables de las pérdidas en este último grupo deberían ser los integrantes del Grupo A. Por consiguiente, sería lógico que sean ellos quienes lleven las cabezas de sus víctimas. Pero ocurre lo contrario, todas las cabezas cortadas están del lado del Grupo B:

- una, correspondiente probablemente a la víctima reproducida en la segunda hilera del lado izquierdo, yace cerca del cuerpo decapitado (Figura 1, Anexo 1: B.II.2),

- hay otro cuerpo en la segunda hilera del lado derecho (Figura 1, Anexo 1: B.II.4) y aquí las posibilidades son dos: o la cabeza asociada es la que lleva en la mano el guerrero de la primera hilera (B.I.3, note que la pintura facial del guerrero en cuestión y la de la cabeza cortada son idénticas) o la que lleva el guerrero de la tercera hilera (Figura 1, Anexo 1: B.III.3).

En todo caso tenemos tres cabezas cortadas y solo dos cuerpos decapitados: ¿a quién corresponde la tercera cabeza? ¿Y por qué los cuerpos y las cabezas están solo de lado del Grupo B?

En el Grupo B no hay representación clara de un líder, equivalente (comparable) a los dos incas del Grupo $\mathrm{A}^{4}$. Tampoco hay representación de collas y chunchus, lo que constituye otra característica distintiva de este grupo.

Sin embargo se pueden diferenciar como mínimo cuatro subgrupos de integrantes que tentativamente denominaremos "étnicos":

- el más distintivo es el compuesto por tres (o hasta cuatro) integrantes, caracterizados por un particular tipo de tocado en forma de un casco provisto de una "trenza" (¿o cola?); estos están representados en la primera y tercera hilera (Figura 1, Anexo1: B.I.1, B.I.2, B.II.3 y B.III.1). Volveremos al análisis de este particular adorno en la parte final de este estudio,

- otro esta integrado por dos personajes identificables también por un particular tipo de tocado en forma de dos elementos verticales encima de la cabellera, parecidos a alas (Figura 1, Anexo 1: B.III.2 y B.III.4),

- un tercero está constituido también por dos personajes, en la primera y tercera hilera, identificados por un tipo de uncu negro - rojo (Figura 1, Anexo 1: B.I.4 y B.III.3), - en la hilera inferior encontramos a dos personajes, que, a juzgar por el tipo de escudo y motivos en sus túnicas, pueden ser identificados como incas (Figura 1, Anexo 1: B.IV.3 y B.IV.4). La posible interpretación de su presencia en el Grupo B se discutirá en la parte final del texto.

Asimismo, cabe resaltar la presencia de un curioso personaje en la hilera superior: está desprovisto de cualquier arma, sin embargo sus manos estan representadas de manera particular -parecen garras. Es también notable la representación de su rostro: boca abierta, en la que se nota algo como un colmillo puntiagudo (Figura 1, Anexo1: B.I.5).

Finalmente, otro rasgo que diferencia al Grupo A del B: solo entre los integrantes del B aparece pintura facial de color rojo, que se nota en 10 de los 17 individuos (incluyendo la cabeza cortada en la primera hilera).

Lo que parece resaltar a primera vista, es que en el conflicto que opone el Grupo A al Grupo B, el que lleva la ventaja es el primero, encabezado por dos incas. Esta situación está aparentemente señalada por la presencia de víctimas decapitadas únicamente del lado del Grupo B, paralelamente a la de cautivos de este grupo en el lado del Grupo A. Otro detalle que apoya esta interpretación es la presencia en el Grupo A de un personaje que toca una bocina o trompeta (Anexo 1: A.II.3), accción que simboliza el triunfo y poder (Battock 2013; Gruszczyńska-Ziółkowska 1995:132; Gudemos 2009).

En el objeto no hay ninguna representación de españoles y tampoco de cualquier artefacto de origen europeo. A este rasgo nos referiremos en la parte final del análisis.

Resumiendo, se trata aparentemente de una escena narrativa que pudo ser bien comprensible para el observador andino contemporáneo, sin que fuera necesario (para este último) recurrir a algún tipo de comentario en forma de tocapus (o inscripciones alfabéticas) $)^{5}$.

\section{Análisis Estilístico-Formal}

Dejando de lado por el momento la interpretación del significado de la escena, dediquemos unas palabras al problema estilístico. 
Tomando como punto de referencia la clásica división de J. H. Rowe, el objeto analizado pertenece al Estilo Libre (Free Inca Style), caracterizado por la representación relativamente realista de las figuras humanas, en actitudes no estáticas, como en el Estilo Formal (Formal Style), sino en movimiento (Rowe 2003 [1961]:318-320).

Sin embargo, hay que notar que el objeto exhibe una variante particular del Estilo Libre, cuyos rasgos distintivos son los siguientes:

- En la decoración del objeto analizado no se percibe el horror vacui típico de la mayoría de vasos del Estilo Libre, en los que los espacios entre los personajes representados están rellenados con flores u otros elementos decorativos (Figura 2). Al contrario, los personajes aparecen en un fondo liso, desprovisto de cualquier detalle adicional.

- Los rasgos faciales parecen más "individualizados" y mucho menos estereotipados que en la mayoría de las representaciones del Estilo Libre. En este último, tanto los rostros andinos como los europeos están representados según el mismo patrón ${ }^{6}$ (Figura 2).

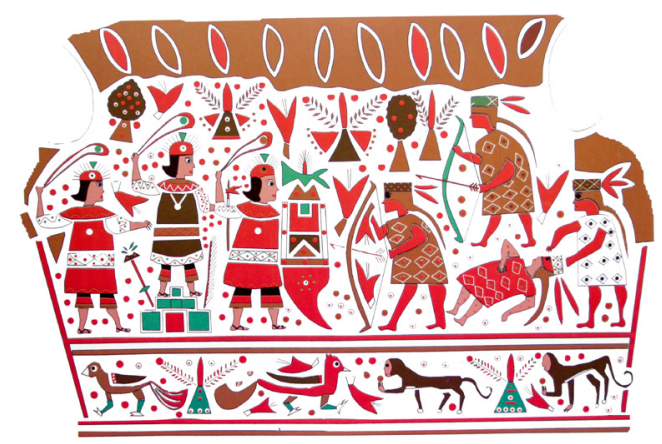

Figura 2. Escena de la batalla de los Incas con Antis representada en el quero $\mathrm{n}^{\circ} 70$ VA 368, Ethnologishes Museum Berlin. Típico ejemplo del Estilo Libre (Free Inca Style) según J. H. Rowe (1961, 2003). Nótese el carácter esquemático de los rasgos faciales de los protagonistas y el horror vacui, tendencia de rellenar todos los espacios libres con motivos florales, entre otros (dibujo de Oriana Wichrowska).

Scene of the battle of between the Incas and Antis represented in the quero $n^{\circ} 70$ VA 368, Ethnologishes Museum, Berlin. Typical example of the Free Inca Style, according to J. H. Rowe (1961, 2003). Note the schematic character of the facial features of the protagonists and the horror vacui, trend of filling up all the free spaces with floral motif, among others. (drawing by Oriana Wichrowska).

- La decoración está claramente repartida en dos paneles, mediante las líneas verticales de color negro. Este rasgo se asemeja más al Estilo Formal, en el que frecuentemente el campo decorado está dividido en partes por dos arco iris.

- No aparece una banda de signos tocapus, elemento muy frecuente en los vasos del Estilo Libre (Rowe 2003).
Buscando analogías estilísticas para este tipo particular de representación podemos señalar algunos objetos de otras colecciones.

El primero es una paqcha de la colección del Museo de América de Madrid con representación de un conflicto armado, donde la escena está delimitada por dos líneas horizontales de color rojo. Hay también ciertos paralelos con el vaso de Hamburgo respecto a los protagonistas representados:

- los personajes están representados sobre un fondo liso sin elementos decorativos adicionales, no hay tocapus.

- Los rasgos faciales son bastante indivualizados, no esquemáticos (Figura 3),

- está representado frontalmente un inca con su escudo del Grupo A (como en el vaso de Hamburgo),

- cerca del inca aparece un chunchu con su arco,

- hay guerreros que llevan cabezas cortadas,

- hay un personaje que toca una bocina.

En grandes líneas, temáticamente la decoración de la paqcha (Figura 3 ) se asemeja a la del vaso de Hamburgo.

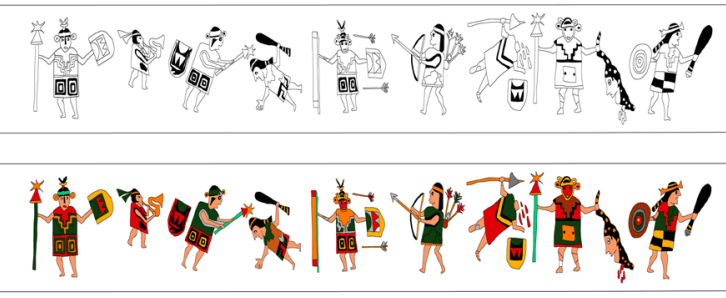

Figura 3. Paqcha de madera inca colonial, objeto $n^{\circ}$ CEO 7570, Museo de América, Madrid. Escena de una batalla en la que se nota la presencia de algunos personaje similares a los del quero de Hamburgo. El principal protagonista parece ser el que lleva la cabeza cortada de su adversario en la mano (dibujo de Sylwia Siemianowska).

Colonial Inca wood paqcha, object $n^{\circ}$ CEO 7570, Museum of America, Madrid. Battle scene in which the presence of some characters similar to those of the quero of Hamburg is noted. The main protagonist seems to be the one who carries the beheaded head of his opponent in his hand (drawing by Sylwia Siemianowska).

Otro objeto de similares características es un tipo de olla de madera, en cuyas paredes vemos tres incas representados frontalmente - todos llevan el mismo tipo de escudo del Grupo A, uno de ellos (el de la izquierda heráldica) lleva la cabeza cortada de un adversario victimado (Figura 4). A diferencia de los dos objetos anteriormente referidos, entre los personajes aparecen elementos decorativos adicionales, flores. Además, en el otro lado del recipiente está representado un símbolo cristiano, un corazón (i?) atravesado por una flecha (¿símbolo del "Corazón Sagrado de Jesús”?), pero ubicado debajo de un arco iris que sale de las bocas de dos leones. Este último motivo parece más bien referirse al Estilo Formal (Rowe 2003) (Figura 4). 

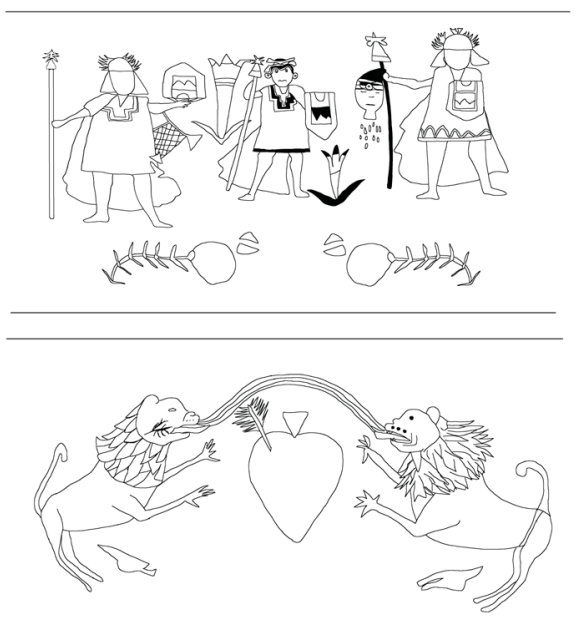

Figura 4. Olla de madera inca colonial, objeto $\mathrm{n}^{\circ} \mathrm{CEO} 7553$, Museo de América, Madrid. Arriba: Tres Incas (¿soberanos?), el de la derecha exhibe la cabeza recién cercenada (véanse las gotas de sangre representadas) de un adversario, posiblemente Chanca. Nótese que los tres llevan el mismo tipo de escudo. Resulta interesante el posible significado de la forma revertida de exhibir el escudo por el personaje de la izquierda. Abajo: Probable representación del "Sagrado Corazón de Jesús" (Dibujo de Sylwia Siemianowska).

Colonial Inca wood pot. Object No. CEO 7553, Museum of America, Madrid. Top: Three Incas (sovereigns?); the one on the right holds the recently severed head of an adversary (note the blood drops), possibly Chanca. Note that all three of them wield the same type of shield. It is worth noting the possible meaning of the reversed way of displaying the shield by the character on the left. Bottom: Probable depiction of the "Sacred Heart of Jesus" (drawing by Sylwia Siemianowska).

Buscando similitudes estilístico-temáticas, en el Museo Tiahuanaco de La Paz encontramos un quero (MNA1705649) en el que están representados dos incas uno de ellos lleva la cabeza cortada, cuya parte superior está pintada en rojo. El inca que lleva un escudo del Grupo A, pisa el cuerpo decapitado de su víctima (Figura 5).

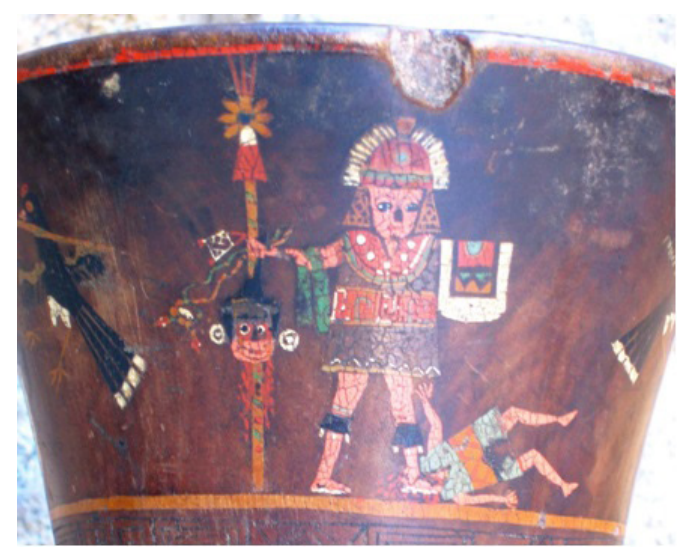

Figura 5. Un soberano inca con la cabeza cortada de su adversario (¿Chanca?) en la mano, en actitud de pisar el cuerpo de su víctima. Quero $n^{\circ}$ MNA1705649, Museo Tiahuanaco de La Paz Bolivia (foto de Mariusz Ziółkowski, cortesía del Museo).

An Inca sovereign with the severed head of his adversary (Chanca?) in his hand, stepping on the body of his victim. Quero No. MNA1705649, Museo Tiahuanaco de La Paz, Bolivia (photo by Mariusz Ziótkowski, courtesy of the Museum).
Un vaso procedente de la colección del Museo Etnográficode Munichostentatambién ciertas similitudes con los cuatro objetos referidos anteriormente. En la escena figurativa presente en este vaso, relativamente poco compleja, están representados dos personajes masculinos con atributos que permiten identificarlos como incas (posiblemente el mismo Sapan Inca) y dos centauros armados con arcos y flechas (Figura 6). Esta parece ser una versión resumida del motivo "Guerra de los Incas con los Antis" (escena n 4, Ziółkowski 2009), en la que los centauros representarían a las poblaciones selváticas consideradas por los serranos como "salvajes". Lo excepcional en este quero son cuatro inscripciones cortas en alfabeto latino, realizadas con la misma técnica de laca incrustada que la decoración figurativa. Como se ha demostrado en un estudio anterior dedicado a este objeto, se trata aparentemente de los nombres de dos soberanos incas -Huayna Capac y Manco Inca- más una versión corrupta del nombre "Andis/Antis" para denominar a las figuras de los centauros (Ziółkowski 2009:324-325). Es también de notar que la parte "narrativa" de la representación está circunscrita por dos líneas horizontales de color rojo. En este espacio así delimitado no aparecen ni plantas ni otros elementos decorativos, exactamente como en el vaso de Hamburgo.

La forma de representar los rasgos faciales de los personajes se asemeja también al estilo de este último objeto, así como al de los dos recipientes de la colección del Museo de América descritos anteriormente.

Resumiendo, tanto el vaso de Hamburgo como los tres objetos descritos de manera sumaria comparten ciertos rasgos estilísticos y temáticos comunes:

- presentan una variante estilística del Estilo Libre, pero con ciertas referencias al Estilo Formal,

- la principal escena está enmarcada en unos "paneles", mediante el uso de líneas rectas (negras o rojas) que, en tres de los cuatro casos analizados, delimitan la parte con representación narrativa,

- la forma de representar a los individuos, y en particular sus rasgos faciales, es relativamente "individualizada" y no esquemática como en los casos clásicos del Estilo Libre (Figura 2),

- en todos los objetos está representada una temática bélica, - en tres de los cuatro objetos se nota el motivo de la cabeza cortada,

- también en tres objetos hay efigies de chunchus o moradores de la selva,

- entre los protagonistas de la contienda aparecen los soberanos incas; si bien la vestimenta de estos últimos cambia de un objeto a otro, todos ostentan el mismo tipo de escudo del Grupo A. Este elemento, junto con las inscripciones en alfabeto latín en el vaso de Munich, testimonian el interés de representar de manera clara e inequívoca a personajes históricos concretos, en un contexto de hazañas bélicas que les fueron atribuidas.

Considerando los rasgos comunes de los cuatro objetos, se puede postular tentativamente, que pudieron 

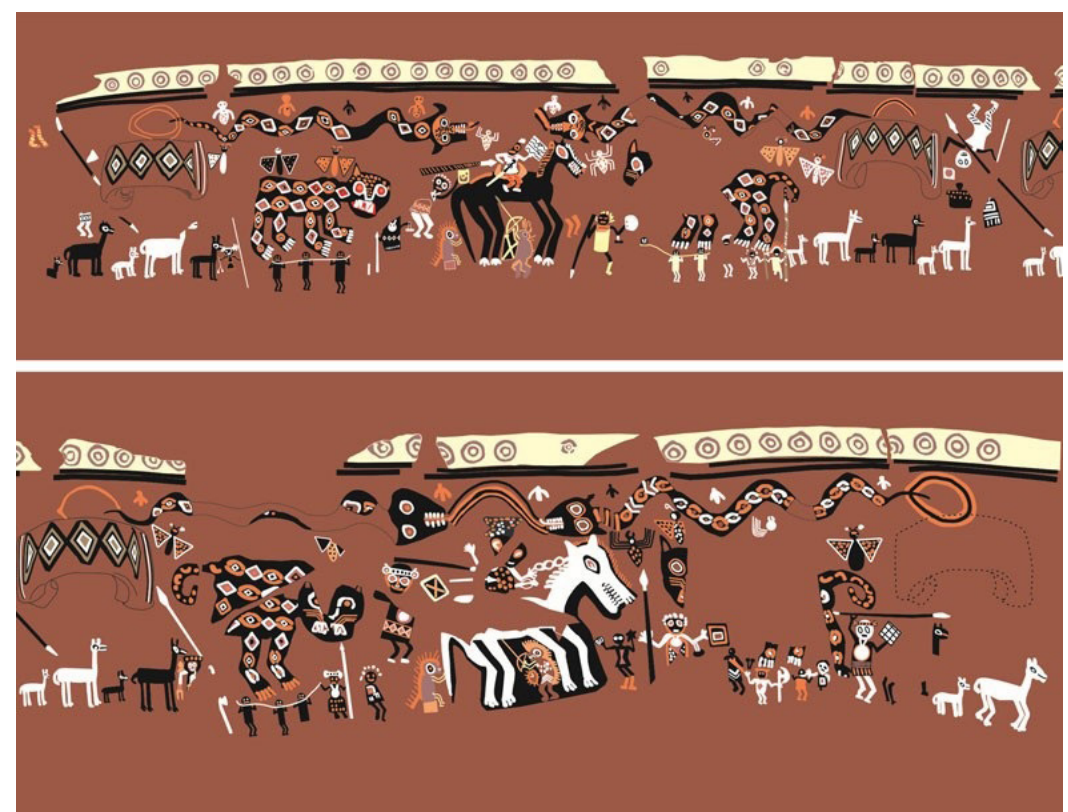

Figura 6. Reconstrucción gráfica de la decoración del cuenco de Tendi Pampa (Vilcabamba). Nótese la calidad inferior de la decoración comparando p. ej., con el recipiente inca representado en la Figura 7. Dibujo Arturo Rivera (Artzi et al. 2019:161, fig. 4).

Graphic reconstruction of the decoration of the Tendi Pampa bowl (Vilcabamba). Note the inferior quality of the decoration compared with the Inca vessel represented in Figure 7. Drawing by Arturo Rivera (Artzi et al. 2019:161, fig. 4).

haber sido basados en un mismo modelo (o modelos) tanto formal como estilístico y temático.

¿Cuál pudo haber sido este supuesto modelo? ¿Y a qué evento se refiere la representación?

\section{Algunas Consideraciones de Carácter Cronológico acerca de los Orígenes de la Tradición Pictórico-Narrativa Inca y de su Contenido Temático}

La clásica tipología estilístico-cronológica de los queros fue propuesta hace años por Rowe $(1961,2003)$. En ella el conocido investigador propuso una división básica de las escenas en dos estilos, que representaban, según él, etapas sucesivas: un primer estilo llamado Estilo Formal (Formal style), y otro más tardío, el Estilo Libre (Free Inca Style). El primero habría aparecido ya en la segunda mitad del siglo XVI, y alrededor de 1630 habría evolucionado al Estilo Libre (Free Inca Style) (Rowe 2003 [1961]:320). La clasificación propuesta por Rowe está basada principalemente en el análisis estilístico de vestidos y otros artefactos de origen europeo representados en los vasos. Más tarde, Thomas Cummins demostró que el llamado Estilo Libre pudo en realidad haber sido, al menos en parte, contemporáneo al Estilo Formal, ya a finales del XVI (Cummins 2002:178-187). Sin embargo, ambos investigadores compartían la opinión de que la tradición de representaciones figurativas de este tipo aparece solo en la Colonia, a mediados del siglo XVI, y no tiene antecedentes prehispánicos conocidos, al menos en lo que respecta a las decoraciones de los queros ${ }^{7}$.

Pero, admitir la evidencia de que los vasos ceremoniales en madera adquirieron la función de soportes de representaciones figurativas solo en tiempos de la Colonia (Ziółkowski 1979) no equivale a la aprobación de que este tipo de representaciones careció de antecedentes más tempranos (hasta prehispánicos) en otros soportes materiales.

Las evidencias más concretas de la existencia de una tradición pictórica figurativo/narrativa inca anterior a la conquista española proceden del estudio de la cerámica. Barraza (2012) había demostrado la presencia de representaciones de cuatro tipos de acllas y un tipo de funcionarios o "acllas" masculinos en la cerámica de tipo Cusco Policromo Figurado. El estudioso fecha los objetos analizados a fines del periodo Prehispánico o a los primeros decenios de la Colonia (Barraza 2012).

Recientemente se ha interpretado la decoración de un cuenco excavado en Espíritu Pampa como representación de la conquista interpretada desde la óptica y programa político de la corte inca de Vilcabamba (Bat Ami et al. $2019)^{8}$. El objeto analizado ha sido encontrado en un conjunto ceremonial deliberadamente quemado por los incas, hecho que, conjuntamente con dos fechados radiocarbónicos obtenidos en base a las muestras sacadas de este contexto, permite avanzar una fecha alrededor de la caída del reducto de Vilcabamba, es decir, por $1570^{\circ}$. Es de observar que el objeto mencionado parece unas decadas 
más tardío que los cerámicos analizados por Barraza Lescano. Además, comparado con estos últimos, luce una calidad sensiblemente inferior tanto en lo que respecta al aspecto técnico como al estético/artístico (Figura 6). Esta constatación es de interés, porque parece indicar que al menos a inicios del periodo Colonial se observa un declive de la calidad de la producción artística/ artesanal andina, fenómeno sin duda alguna ocasionado por factores sociopolíticos resultantes de la caída del aparato administrativo inca y de su sistema de organización y control del trabajo. De esto se puede sacar una conclusión importante para el presente estudio: que la calidad artística inferior de un artefacto comparado con otro no es necesariamente debida a su mayor antiguiedad -a veces puede ser todo lo contrario $^{10}$.

Es también posible que el paso de las representaciones en cerámica a la representación en vasos (u otros objetos) de madera pudo haber ocurrido unos decenios antes de lo postulado por Rowe y Cummins. Paz Cabello Caro (2006) estudió la escena figurativa en una paqcha al parecer procedente de la región de Trujillo y llegó a la conclusión de que el desfile de soldados armados con armas de fuego con una bandera de Carlos $\mathrm{V}$, representado en el objeto, corresponde a la ceremonia de entrega de las armas a la Ciudad de Trujillo en 1538. La estudiosa avanza una fecha bien temprana para la elaboración del objeto -entre 1538 y 1540 (Cabello 2006:166)- lo que implicaría la existencia ya por aquel entonces de especialistas familiarizados con tal clase de representaciones figurativas. Acerca de este último punto cabe recordar que María Rostworowski de Diez Canseco (1977), en su clásico estudio sobre oficios y profesiones tradicionales de los indígenas de la $\operatorname{Costa}^{11}$, cita documentos coloniales en los que aparecen enumerados los pintores como artesanos itinerantes. Esta autora hace una vinculación entre este oficio particular y los registros históricos, como las Tablas de Puquin Cancha, de los que se tratará a continuación (Rostworowski 1977:239-240). La existencia de tal tradición pictórica también en la Costa Central en los periodos prehispánicos tardíos (cultura
Ychma) se ve confirmada por los murales del Templo Pintado de Pachacamac, en los que aparecen. entre otras, representaciones de seres humanos en actitud de procesión (Marcone 2003).

Finalizaremos esta presentación sumaria de ejemplos de representaciones narrativas tempranas con un objeto único, un gran recipiente de piedra con decoración figurativa en las paredes (Figura 7). La descripción resumida del objeto, según la ficha del British Museum:

Es un recipiente o cuenco cilíndrico de piedra tallada con dos asas redondeadas; inscrito con escenas figurativas inusuales: en un lado, un gran disco solar central con una cara está flanqueado por dos figuras de pie con las manos en el pecho. Directamente debajo del disco solar hay dos figuras arrodilladas, una frente a la otra con las manos cruzadas delante de ellas. Entre ellos hay un pequeño objeto en forma de diamante con una cara. La pequeña figura de culto parece ser la manifestación terrenal o representante de la deidad solar. Por otro lado, una escena complementaria tiene una figura masculina y femenina en el centro, posiblemente el Inca y su reina, que son el foco de una procesión compuesta por una mujer con un huso, un jorobado y llamas conducidas desde ambos lados. (Colin McEwan 2009:92-93. Traducción al español de los autores) $)^{12}$.

De factura inca, el objeto puede ser fechado a fines del periodo Prehispánico o los primeros años de la Colonia, siendo la cronología más antigua la de mayor probabilidad. Esta evaluación se fundamenta en el tamaño respetable del objeto ${ }^{13}$, la excelente calidad técnica de su ejecución, el temario religioso inca de la escena, más algunos detalles de la misma (la figura itifálica del Inca, entre otros).

Esta revisión sumaria de los objetos enumerados más arriba testimonia la presencia en el arte inca de una tradición de representaciones pictóricas de carácter narrativo, muy probalmente de orígen prehispánico.

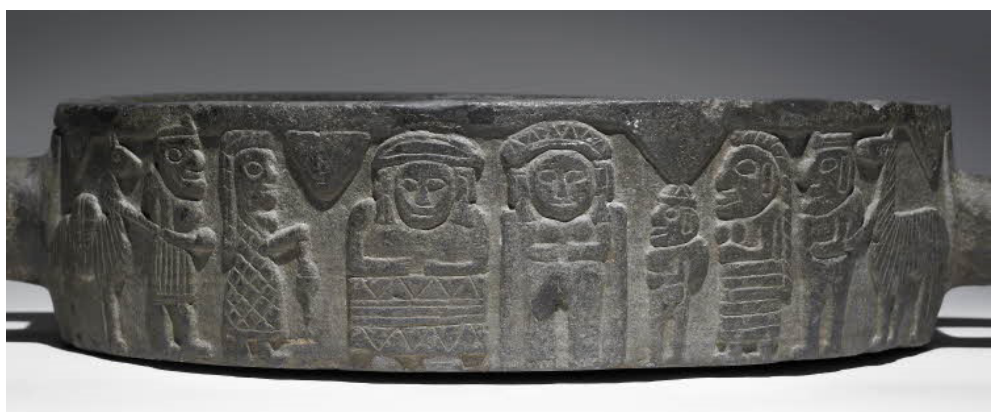

Figura 7. Recipiente de piedra inca con decoración figurativa en las paredes (foto: cortesia del British Museum, Londres).

Inca stone vessel with figurative decoration on the walls (photo: courtesy of the British Museum, London). 
La existencia de tales representaciones con función de registros históricos pictóricos está tambien confirmada por fuentes escritas. La referencia más conocida sobre "pinturas históricas" de los incas es, sin duda, la relativa a las famosas “Tablas de Poquen Cancha”, hoy desaparecidas, pero que existieron y fueron consultadas hasta por lo menos mediados de los años 1560, a juzgar por los testimonios del padre Cristobal de Molina y de Pedro Sarmiento de Gamboa, entre otros (Molina 1989 [1575]:49-50; Sarmiento de Gamboa 1906 [1572] Cap. 9:31).

Aparentemente el uso de tales representaciones pictóricas no se limitaba a Poquen Cancha, a juzgar por las siguientes recomendaciones de la Real Cédula del 20 de diciembre de 1553:

Y demas de la informacion que hubieredes de los testigos, hareis traer ante vosotros cualesquier pinturas o tablas o otra cuenta que haya de aquel tiempo por do se pueda averiguar lo que esta dicho; y hareis que los religiosos los busquen y soliciten entrellos, los que supieren lengua ${ }^{14}$.

Las características exactas y contenido de estos registros siguen siendo objeto de discusión entre los especialistas, tema abordado en otros lugares (Marco Dorta 1975; Martinez et al. 2014; Szemiński 2005; Ziółkowski 2009, 2018; Ziółkowski etal. 2008). Uno de los temas más debatidos dentro del marco de estas polémicas es el de las supuestas copias o reinterpretaciones (parciales o íntegras) de estos "tablones" que hubiesen sido realizadas en el periodo Colonial en diferentes tipos de materiales. Entre los objetos considerados como posibles copias de los archivos de Poquen Cancha mencionemos en particular a los "paños" genealógico-históricos realizados en 1571 (hoy desaparecidos) por artistas indígenas por encargo del Virrey Toledo (Barnes 1996; Marco Dorta 1975; Gisbert 1980:117 y ss.).

Sin entrar en detalles de esta profusamente debatida materia, nos limitaremos solo a algunos aspectos de esta discusión, de importancia para el tema del presente texto, es decir, la cuestión de las efigies de los incas representados en el contexto de ciertos tipos de conflictos armados.

Los cuatro paños realizados en 1571 por orden del Virrey Toledo presentaban no solo la sucesión genealógica de los incas sino también la relación jerárquica entre los diferentes integrantes de la élite inca (incluyendo las Coyas): “[ ... ] estaban escriptos y pintados en los quatro paños los bultos de los ingas con las medallas de sus mujeres y ayllos [ ... ]" (Testimonio de Alvaro Ruiz de Navamuel 1572, citado, en Marco Dorta 1975:69).

Aparentemente la disposición de los diferentes retratos implicaba cierto tipo de orden jerárquico y de importancia, lo que escandalizó a la viuda de Sayri Tupac, la Coya María Cusi Huarcai durante la presentación ofical de los paños a los representantes de la élite inca en abril de 1572: "Viendo esto, doña María Cusi Guarcai, mujer del Inca que murió [Sayre Tupac] (...) hermana legítima de Tito Cusi Yupanqui (...) y viendo que una hija de Paulo Inca, llamada doña Juana, estaba pintada encima de la dicha doña María, se enojó y dijo allí: "como se sufre que el padre de don Carlos y él estén [en] más preminente lugar, y su hermana siendo bastarda, que mi padre [Manco] mi hermano Tito Cusi y yo, siendo legítimos y ainsi se fué con otros yngas sus deudos a quejarse al Virrey sobreeqo..." 15 .

Estos lienzos, que el Virrey Toledo había enviado a España, se perdieron en el incendio del Alcázar de Madrid en 1734, pero fueron aparentemente copiados en diferentes momentos. De una (¿unas?) copia se aprovecharon para los dibujos de los Reyes Incas tanto los artistas anónimos que ilustraron los dos manuscritos de Martín de Murúa ${ }^{16}$, como Guaman Poma de Ayala, mientras que el original sirvió de modelo al miniaturista Antonio Maria Antonazzi para una serie incompleta de retratos de los reyes Incas realizada entre 1655 y 1658 en Madrid por encargo de Camillo II Massimo, enviado del Papa a la corte española (Estenssoro 1994) ${ }^{17}$. En lo que respecta al tema del presente estudio, es importante observar que estos lienzos no pudieron haber servido de modelo para la escena reproducida sobre el quero de Hamburgo, ya que no representaban escenas narrativas sino retratos.

Pero no eran estos los únicos lienzos que se confeccionaron para documentar por vía de representaciones gráficas tanto la historia de los incas como, lo que es también de importancia, los eventos de la conquista. Marco Dorta cita un muy interesante pleito en el que uno de estos lienzos desempeñó el papel de argumento legal:

"Estando en el Alcázar y Palacio Real de Madrid, a diez y ocho días del mes de nobiembre de mil e quinientos y ochenta y seis años, ante mi el escriuano público y testigos yuso scriptos, paresció presente don Pedro Carrillo de Soto, vezino de la ciudad del Cuzco en las yndias del mar oceano en los reinos del Pirú, y me pidió y requirió le dé por fée y testimonio cómo en unos lienços de pinturas de los reyes. que por tiempo antiguo fueron de aquellas partes e ystorias dellos y relación de las Yndias, ansí de los conquistadores como de los reyes de aquellas partes que hubo en tiempo antiguo, que ynbió don Francisco de Toledo, visorrey que fue de aquellas partes, y le sacase un traslado del un capítulo de los dichos lienços, que es del tenor siguiente:

Año de mill y quinientos y treinta y tres años. El baleroso gobernador don Francisco Piçarro, que despues fue marqués, siendo rey de España el católico enperador Carlos 
quinto, por su persona y con ayuda del capitán don Hernando de Soto y pocos conpaneros espanoles dignos de perpétuo nonbre y notable fama, prendió Atagualpa, que se llamaba ynga y señor del Pirú (...). Otrossi yo el dicho escriuano doy fee que bi en el dicho lienço un cauallero del ábito de Santiago que ençima de su caueça, en la pintum del dicho lienço desçia: Soto; tenía asido y presso, a lo que aillí paresçia pintado, al dicho Atagualpa y le lleuaua presso, el qual dicho traslado e fee e ba bien e fielmente sacado de los dichos lienços que allí están escriptos y estaua en poder del guarda xoyas; $y$ de pedimiento del dicho don Pedro Carrillo de Soto lo saqué para lo presentar ante los señores del supremo Real Consejo de Yndias $(. . .)^{18}$.

Es de importancia subrayar que los autores de los lienzos eran indudablemente pintores indios. Lo dice claramente el Virrey Toledo en una carta a Felipe II, que si bien estos artesanos "no tienen la curiosidad de los de allá [Europa]... por la flema y poca pesadumbre de su naturaleza", podría ser de interés enviar algunos a España: "Creo que gustaría Vuestra Magestad tener algunos en las casas de Aranjuez y el Bosque y el Pardo (...) no los he osado ynbiar sin licencia, que no es gente con quienes menester hacer más asiento que dalles la comida y la mánta con que se cubren"19.

Resumiendo estas informaciones:

1. Las fuentes históricas, respaldas por algunas evidencias arqueológicas, dan testimonio de la existencia de representaciones figurativas de los eventos históricos, tanto del tiempo del Incario como de la Conquista.

2. Las escenas son de carácter narrativo y representan a los protagonistas en acción: "Soto; tenía asido y presso, a lo que ailli paresçia pintado, al dicho Atagualpa y le lleuaua presso".

3. Los orígenes de esta tradición pictórica son prehispánicas y los autores de aquellas son profesionales indígenas y no europeos. Sin embargo, en pocos decenios desde la Conquista, las representaciones figurativas se ven complementadas por inscripciones alfabéticas, mediante las que se denominan a los protagonistas de los eventos retratados, así como, aparentemente, comentarios o precisiones acerca del sentido de las escenas representadas: bi en el dicho lienço un cauallero del ábito de Santiago que ençima de su caueça, en la pintura del dicho lienço desçia: Soto.

4. Las representaciones aluden a temas de máxima importancia, tanto a nivel histórico (e.o la captura de Atahuallpa, la sucesión de los soberanos incas etc.), como ideólogico-religioso: "las fábulas de las creaciones de Viracocha, que van en la cenefa del primer paño, porfundamento y principio de la historia, cada cosa por sí distintamente escripto y señalado de la rúbrica de mi el presente secretario" (Alvaro Ruiz de Navamuel en Marco Dorta 1975: 69).

\section{A modo de conclusión: ¿a que evento histórico (o legendario) se refiere la escena en el quero de Hamburgo?}

Como ya hemos formulado al final de la primera parte del presente texto, la escena en el quero de Hamburgo, reproduce un evento muy importante para la tradición mito-histórica inca. La alta calidad técnica y artística del objeto y la complejidad de la imagen suponen, que este había sido elaborado por encargo de una persona de alta posición social y buena condición económica, es decir, por un miembro de la élite inca. Tuvo entonces que tratarse de un evento emblemático para la identidad del grupo inca en relación a otras etnias del Tawantinsuyu.

La falta de representación de cualquier personaje $o$ artefacto de origen europeo presume que la escena se refiere a un acontecimiento bélico anterior a la conquista, relatado con un lujo de detalles considerados de importancia para la narración. Esta última deducción se basa en la individualización de los 36 participantes de la contienda, en lo que se refiere a sus respectivos trajes y armas.

Como ya lo hemos mencionado, entre los dos grupos de beligerantes se notan significativas diferencias en particular en lo que a la componente étnica de sus integrantes se refiere: el Grupo A, encabezado por dos incas, incluye aparentemente a los habitantes de la selva (Antis) y a los collas, ambas etnias no representadas en el Grupo B.

$\mathrm{Al}$ considerar diferentes posibilidades, la que nos parece la más probable (aunque no sin reserva -ver más adelante), es que se trata de la representación del conflicto entre incas y chancas ${ }^{20}$. Los principales argumentos a favor de tal interpretación se basan en cuatro elementos iconográficos:

\section{Motivo de la cabeza cortada}

En la escena analizada aparecen tres cabezas cortadas pertenecientes indudablemente a los integrantes del Grupo B. Notemos que el motivo de la cabeza, cercenada al adversario en el campo de batalla aparece en la tradición histórica inca principalmente, aunque no exclusivamente, en relación a la/s batalla/s contra los chancas. Betanzos dice al respecto que "en el sitio do la batalla se diera, y para que de ella hubiese memoria, en presencia de todos los de su campo, mandasen hincar muchos palos de los cuales fuesen ahorcados y, después de ahorcados, les fuesen cortadas las cabezas y puestas en lo alto de los palos" (Betanzos 1987 [1551] I p., Cap. $\mathrm{X}: 45)^{21}$. Una referencia parecida se encuentra en la crónica de Sarmiento de Gamboa (Sarmiento de Gamboa 1906 
[1572] Cap. 28:65). Ramos Gómez, en su estudio de las representaciones en cuatro queros y un lienzo colonial del enfrentamiento entre incas y chancas, hace resaltar la presencia en todos estos objetos del motivo de la cabeza cortada del chanca vencido (Ramos 2002). A estas evidencias se pueden sumar los tres objetos (la paqcha, la olla del Museo de Madrid y el quero del Museo de La $\mathrm{Paz}$ ) descritos anteriormente. Pero hay que reconocer que faltaría explicar un detalle algo extraño, a saber: ¿por qué, a diferencia de los siete ejemplos de escena del conflicto inca-chancas y su desenlace, en el quero de Hamburgo las cabezas cortadas no figuran en manos de los incas y de sus aliados, sino en las de los integrantes del supuesto "campo perdedor" (Grupo B)?

\section{Participación de antis y collas del lado inca en la contienda}

Entre los integrantes del grupo A, encabezado por los incas, hemos identificados a tres antis y dos (o hasta tres) collas. Recordemos al respecto que, según Betanzos los ejércitos chancas, paralelamente al avance contra el Cusco, entraron y conquistaron territorios en Antisuyu y en Condesuyos. Respecto a esta última región el cronista dice, que los ejércitos chancas: “(...) ganaron e sujetaron, yendo desde el pueblo de Paucaray por la provincia de Condesuyo hasta llegar a los Chichas [Chibchas], cincuenta leguas más allá de los Charcas" (Betanzos 1987 [1551], I p., Cap. VI:24).

Esta última localización corresponde más bien a la región del Collasuyu. En tal caso la presencia de antis y collas del lado de los incas en la escena del quero de Hamburgo resultaría lógica (Figura 1).

La actuación de los antis en el bando inca se ve confirmada, aunque de manera indirecta, por otros datos históricos. Sarmiento de Gamboa, al relatar la segunda batalla de los incas contra los chancas en Ichopampa, enumera las armas usadas por cada bando: "Punaban los Chancas con sus lanzas largas, los ingas con hondas, porras, hachas y flechas cada cual para defender su persona" (Sarmiento de Gamboa 1906 [1972] Cap. 28:65).

La mención de "flechas" supone el uso de arcos, arma preferida de los antis y atribuida exclusivamente a estos últimos en la tradición iconográfica colonial. El fragmento citado contiene también otra información importante, la referencia a las "lanzas largas" de los chancas. Esto corresponde bien a la representación de las armas usada por seis de los guerreros integrantes del Grupo B (Figura 1, Anexo 1).

Finalmente, otro detalle más: las caras pintadas en rojo de los integrantes del Grupo B. Tal tipo de pintura facial se usaba como señal de triunfo ${ }^{22}$, detalle adecuado para el caso de los chancas, quienes atacaron el Cusco después de las victoriosas campañas militares llevadas a cabo en el Antisuyu y el Condesuyos (y Collasuyu -véase más atrás).

\section{Presencia de algunos incas (¿?) en el Grupo B.}

Entre los integrantes del "Grupo B" notamos la presencia de dos (o hasta tres) personajes, que llevan escudos parecidos a los del Inca (A ).

En la crónica de Betanzos encontramos una posible elucidación de este hecho:

los de Xaquixaguana; y todos juntos fueron delante de Ynga Yupangue y echáronsele por tierra, a los cuales los de Ynga Yupangue los quisieron matar por haber visto la muerte de los suyos, e Ynga Yupangue se lo defendió, diciendo que no los matasen, que si con los changas se habían hallado, que sería por haber sido la junta en su tierra, e que no podrían hacer otra cosa, y ellos, ansimismo, decían las mismas palabras e daban la misma satisfacción. Y, luego, mandó Ynga Yupangue que por cuanto eran orejones, que luego les fuesen tresquilados los cabellos (...) (Betanzos 1987 [1551], I p. Cap. X:44).

\section{Los tocados de los guerreros del Grupo B}

Una diferencia interesante entre los integrantes de los grupos A y B es la forma de sus respectivos tocados: concretamente, no hay ni un solo caso de similitud en este aspectoentre los dos bandos. Puestos aparte los característicos tocados cónicos de los dos (o tres) collas y el chucu del Soberano Inca (A.I.3), los miembros restantes del Grupo A llevan o un llauto (elemento ausente entre los integrantes del grupo adverso) o un tipo de casco semiesférico (chucu). En cambio los tocados de los integrantes del Grupo B son más diferenciados, entre estos destacan las "colas" o "trenzas" que adornan a tres beligerantes. El elemento en cuestión, de color pardo con la punta negra, parece atado a un casco y les cae en las espaldas de los individuos. La primera asociación podría ser que se trate de la cola de un animal (¿zorro?). Sin embargo, aunque se conocen máscaras en forma de hocicos de animales o hasta pieles integras con las que los beligerantes pueden vestirse, en este caso claramente se trata de un elemento largo, pero no es ni un hocico ni una piel íntegra, tampoco una pluma o ala de ave por ser el detalle analizado demasiado estrecho y largo.

La otra posibilidad es que se trate de un tipo de trenza. Acerca de ello tenemos un testimonio de Cieza de León: [Chancas] "todos los más traen cabellos largos entrenzados menudamente, puestos unos cordones de lana que les vienen a caer por debajo de la barba" (Cieza de León 2005 [1553], cap. XC:236). Pero esta 
descripción no concuerda bien con la imagen del elemento analizado.

Dejemos por el momento sin solución definitiva este detalle y pasemos a otro tocado, representado en dos individuos. Se trata de dos elementos verticales encima de la cabellera, que parecen como alas de aves. Se ha detalladamente analizado el motivo de las aves en especial en relación a los chancas, pero en las figuras existentes de este motivo se trata más bien de alas o aves enteras en las espaldas de los guerreros chancas, pero no en forma de tocados (Martinez et al. 2014).

Concluyendo, a título tentativo estamos avanzando la hipótesis de que en el quero de Hamburgo está representado el conflicto entre los incas y los chancas. La escena parece basada en un relato (o modelo iconográfico) detallado, en el que se ha representado de manera pormenorizada a los participantes de la contienda, haciendo particular hincapié en su afiliación étnica. La escena analizada es la más compleja que se conozca, probablemente las pintadas en otros objetos enumerados en el presente texto son versiones simplificadas del mismo relato/modelo.

Dada la importancia que en la tradición mitohistórica inca recogida por los cronistas coloniales se le dió a esta contienda, podemos suponer que esta formaba también parte de las historias representadas en los tablones de Poquen Cancha. De ser así, el quero de Hamburgo podría representar la versión más cercana a aquel posible original. Y probablemente también a nivel cronológico. Nos tomaremos la libertad de avanzar acerca de este tema un hipótesis algo audaz: podría ser que el quero de Hamburgo hubiera sido elaborado entre los años 1550 e inicio de 1570 . Resumamos brevemente los argumentos ya esbozados antes, en apoyo a tal identificación cronológica:

1. Está, sin lugar a dudas comprobada la existencia, como mínimo desde mediados del siglo XVI, de artesanos indígenas especializados en el arte de pintar representaciones figurativas de carácter narrativo, lo que testimonia la cédula de 1553.

2. Los tablones de Poquen Cancha, supuestos modelos para al menos parte de los motivos históricos representados posteriormente en los queros, estuvieron accesibles como mínimo hasta los años de 1560, cuando los consultó el padre Cristobál de Molina.

3. La escena representada en el quero de Hamburgo comprende 36 personajes, pero lo que más llama la atención es el carácter individualizado de estas representaciones: no hay dos personajes vestidos de manera idéntica. Este afán de personalizar a los protagonistas supone la importancia de clasificarlos dentro del marco de una división étnico-social compleja. Notemos que esta variedad está ausente en las obras clasificadas, de manera bien fundada e inatacable, en los siglos XVII y XVIII. Tomemos un ejemplo bien conocido: el cuadro de la "Descención de la Virgen sobre el Sunturhuasi" de fines del s. XVII. Si bien está representado un numeroso ejército inca, todos los soldados llevan en el traje típico de los soberanos incas o como mínimo de la aristocracia inca (Estensorro 2005:11 y ss.); visiblemente el artista no tuvo interés (¿o le faltaba un conocimiento adecuado?) en representar a los soldados rasos y tampoco a diferenciar su pertenencia étnica, cosa a la que Guaman Poma todavía prestaba mucha atención.

4. El quero de Hamburgo estaría, a nivel cronológico enmarcado, por un lado, por la "paccha de Trujillo" (a condición de aceptar la datación de 1538-1540 propuesta por Paz Cabello Caro) y por el otro, por el "baúl de La Paz" de la segunda mitad del siglo XVI, según la datación de Teresa Gisbert (2001:89).

Estamos perfectamente conscientes de que la interpretación que hemos esbozado hasta aquí, puede ser sujeta a diferentes críticas, correciones y reinterpretaciones y es lo que esperamos. Para este fin hemos incluido en anexo la documentación pictográfica del quero analizado para facilitar el trabajo analítico de otros especialistas.

Agradecimientos: Quisieramos agradecer al personal encargado de las colecciones (museales y privadas) de las que se pudo sacar la documentación indispensable para el avance de las investigaciones. En particular queremos agradecer la amabilidad mostrada por el personal del Museum Am Rothenbaum. Kulturen und Künste der Welt (MARKK -a. Museum für Völkerkunde, Hamburgo), y en particular a los Doctores Bernd Schmelz y Cristine Chavez, y la Sra. Catharina Winzer, por habernos permitido analizar un objeto único y de gran valor científico, así como por el permiso de publicarlo. Felicitamos al Sr. Paul Schimweg, fotógrafo del Museo, por las excelentes fotos que ha realizado para esta publicación. Debemos tambien las gracias a la Magister María Mercedes Martínez Milantchí del Departamento de Africa, Oceanía de las Américas del British Museum, por habernos proportcionado valiosa información acerca de uno de los objetos analizado en el presente texto (Figura 7). Finalmente, quisieramos agradecer al prof. Dr Jan Szemiński por su valiosos y pertinentes comentarios. La parte documental de este estudio ha sido realizada dentro del marco del proyecto titulado " $T$ ' uqapu: el problema de la existencia en el Tawantinsuyu de un sistema gráfico de comunicación", financiado por el National Science Centre of Poland (NCN -agenda del Ministerio de Educación Superior y Ciencia) mediante las becas $1 \mathrm{H} 01 \mathrm{H} 02428$ y N N109243134. Hace también falta resaltar la labor de los evaluadores, cuyas pertinentes e importantes observaciones contribuyeron a la forma final de este estudio. 


\section{Referencias Citadas}

Adorno, R. 2001. Guaman Poma y su crónica ilustrada del Perú colonial: un siglo de investigaciones hacia una nueva era de lectura. Una nueva introducción para la publicación en internet de la Nueva corónica y buen gobierno, mayo, 2001. http://wayback-01.kb.dk/ wayback/20101108104655/http://www2.kb.dk/elib/mss/poma/ presentation/index-en.htm.

Artzi, B., A. Nir y J. Fonseca. 2019. Los fragmentos de Vilcabamba, Perú: Un testimonio iconográfico excepcional de la visión andina sobre el enfrentamiento entre indígenas y españoles. Latin American Antiquity 30 (1):158-176.

Barnes, M.1996. A lost Inca history. Latin American Indian Literatures Journal 12 (2):117-131.

Barraza, S. 2012. Acllas y Personajes Emplumados en la Iconografía Alfarera Inca: una Aproximación a la Ritualidad Prehispánica Andina. Tesis para optar el grado de Magíster en Arqueología con mención en Estudios Andinos. Pontificia Universidad Católica del Perú. Escuela de Posgrado, Programa de Estudios Andinos, Lima.

Battcock, C. 2013. Santa Cruz Pachacuti: mitos fundantes y elementos simbólicos en el relato de una guerra. Latinoamérica. Revista de Estudios Latinoamericanos 57:277-294.

Battcock, C. 2018. La Guerra entre Incas y Chancas. Relatos, Sentidos e Interpretaciones. Universidad Nacional Autónoma de México, Centro de Investigaciones sobre América Latina y El Caribe, México DF.

Betanzos, J. De 1987 [1551]. Suma y Narración de los Incas. Transcripción, notas y prólogo de María del Carmen Martín Rubio. Ediciones Atlas, Madrid.

Bielatowicz, K. 2007. Wtadca Inkaski na Kolonialnych Keros. Próba.Tesina de maestría, Instytut Archeologii Uniwersytetu Warszawskiego, Warszawa.

Cabello, P. 2006. Continuidad prehispánica y mestizaje en Perú. Una historia de conquistadores narrada en un vaso de libaciones incaico. Anales del Museo de América 14:145-174.

Cieza de León, P. 2005 [1553]. Crónica del Perú. El Señorio de los Incas. Biblioteca Ayacucho, Caracas.

Chávez, E. 1984. Queros cuzqueños. Un ensayo de interpretación descriptiva de la iconografía inca contenida en los queros o vasos de madera del Cuzco. Revista del Museo e Instituto de Arqueología 23:96-107,

Cummins, T. 1988. Abstraction to Narration: Quero Imagery of Peru and the Colonial Alteration of Native Identity. Ph.D. Dissertation, University of California, Los Angeles.

Cummins, T. 2002. Toasts With the Inca: Andean Abstraction and Colonial Images on Quero. (History, Languages, and Cultures of the Spanish and Portuguese Worlds). University of Michigan Press, Ann Arbor.

Cummins, T. 2005. La fábula y el retrato; imágenes tempranas del inca. En Los Incas, Reyes del Perú, editado por T. Cummins, pp. 1-42. Coleción arte y tesoros del Perú, Banco de Crédito, Lima.

De La Jara, V. 1975. Introducción al estudio de la escritura de los Incas. Instituto Nacional de Investigación y Desarrollo de la Educación, Lima.

Marco Dorta, E. 1975. Las pinturas que envió y trajo a España don Francisco de Toledo, Historia y Cultura 9:67-78.
Estensorro, J.C. 2005. La figura del inca y el reino del Perú, de la Conquista a T'upac Amaru II. En Los Incas, Reyes del Perú. Coleción Arte y Tesoros del Perú, editado por T. Cummins, pp. 93-173. Banco de Crédito, Lima.

Flores, J., E. Kuon Arce y R. Samanez Argumedo 1998. Queros. Arte Inka en los Vasos Ceremoniales. Banco de Crédito, Lima.

Gisbert, T. 1980. Iconografía y Mitos Indígenas en el Arte. Gisbert y Cia., La Paz.

Gisbert, T. 2001. El Paraíso de los Pájaros Parlantes. La Imagen del Otro en la Cultura Andina. Plural Editores, La Paz.

González Holguín, D. 1952 [1608]. Vocabulario de la Lengua General de todo el Perú llamada Lengua Qquichua [...] Edición y Prólogo de Raúl Porras Barrenechea. Universidad Nacional Mayor de San Marcos, Lima.

Gruszczyńska-Ziółkowska, A. 1995. El Poder del Sonido. El Papel de Las Crónicas Españolas en la Etnomusicología Andina. Abya-Yala, Quito.

Guaman Poma de Ayala, P. 1615/1616. Nueva corónica y buen gobierno, København, Det Kongelige Bibliotek, GKS 2232 4; www2.kb.dk/elib/mss/poma/

Jiménez de la Espada, M. 1879. Tres Relaciones de Antigüedades Peruanas. Ministerio de Fomento, Madrid.

Jiménez, F. 1994. La iconografía del Inca a través de las crónicas españolas de la época y de la colección de keros y pajchas del Museo de América. Anales del Museo de América 2:5-20.

Levillier, R. 1956. Los Incas. Escuela de Estudios Hispano-Americanos de Sevilla, Sevilla.

Liebscher, V. 1986a. Temenkomplexe der Kero-Ikonographie. Tesis de Doctorado, Departamento de Estudios Clásicos, Universidad Libre de Berlín, Berlin.

Liebscher, V. 1986b. La Iconografía de los Queros. G.H. Herrera Editores, Lima.

Liebscher, V. 1986c. Los Queros. Una Introducción a su Estudio. G.H. Herrera Editores, Lima.

Lizárraga, M.A. 2009. Las élites andinas coloniales y la materialización de sus memorias particulares en los "queros de la Transición" (vasos de madera del siglo XVI). Boletín del Museo Chileno de Arte Precolombino 14 (1):37-53.

Marcone, G. 2003. Los murales del Templo Pintado o Relación entre el Santuario de Pachacamac y la iconografía tardía de la costa central peruana. Anales del Museo de América 11:57-80.

Mártinez, J.L. 2010. 'Mandó pintar dos aves . . .': Relatos orales y representaciones visuales andinas. Chungara Revista de Antropología Chilena 42 (1):157-167.

Mártinez, J.L., C. Díaz, C. Tocornal y V. Arévalo 2014. Comparando las crónicas y los textos visuales andinos: Elementos para un análisis. Chungara Revista de Antropología Chilena 46 (1):91-113

Martínez, J.L. y P. Martínez 2013. Narraciones andinas coloniales. Oralidad y visualidad en los Andes. Journal de la Société des Américanistes 99 (2):41-81.

McEwan, C. 2009. Ancient American Art in Detail. Harvard University Press, Cambridge.

Mesa, J. De y T. Gisbert 1982. Historia de la Pintura Cusqueña. Fundación August N. Wiese, Banco Wiese Ltda., Lima. 
Molina, C. De 1989 [1575]. Fábulas y Ritos de los Incas. Historia 16, Madrid.

Nir, A. 2016. Reconstrucción histórica del ciclo de guerras entre los incas y los chancas. En El Inca y la Huaca. La Religión del Poder y el Poder de la Religión en el Mundo Andino Antiguo, editado por J. Szemiñski y M. Curatola, pp. 121-154. Pontificia Universidad Católica del Perú-Fondo Editorial, Lima.

Perissat, K. 2000. Los Incas representados (Lima - siglo XVIII): ¿supervivencia o renacimiento? Revista de Indias LX (220):623650

Posnansky, A. 1931. Leyendas prehispánicas sobre dos keros. Revista del Instituto de Etnología de la Universidad Nacional de Tucumán 3:93-100.

Ramos, L. 2000. Historiografía de los queros, pajchas y otras vasijas lígneas andinas de época inca y colonial del Museo de América (Madrid). Revista Española de Antropología Americana 30:163-189.

Ramos, L. 2002. El choque de los incas con los chancas en la iconografía de vasijas lígneas coloniales. Revista Española de Antropología Americana 32:243-265.

Ramos, L. 2003. Identificación de parte de la decoración de la pajcha colonial 7572 del Museo de América (Madrid). Revista Española de Antropología Americana, vol. extraordinario, pp. 345- 361.

Ramos, L. 2006. Las vasijas de madera ornamentadas con laca utilizadas por los dirigentes Andinos de la época colonial: función y tipología de sus formas. Revista Española de Antropología Americana 36 (1):85-119.

Rostworowski, M. 1977. Etnia y Sociedad: Costa Peruana Prehispánica. Instituto de Estudios Peruanos, Lima.

Rowe, J.H. 1961. The Chronology of Inca Wooden Cups. En Essays in Pre-Columbian Art and Archaeology, editado por S.K. Lothrop, pp. 317- 342. Harvard University Press, Cambridge.

Rowe, J.H. 2003. La cronología de los vasos de madera inca. En Los Incas del Cuzco. Siglos XVI - XVII - XVIII, editado por J.H. Rowe, pp. 307-343. Instituto Nacional de Cultura Región Cuzco, Cusco.

Sarmiento de Gamboa, P. 1906 [1572]. Geschichte des Inkareiches (Historia Indica). Edición de Richard Pietschmann. Abhandlungen der Königlichen gesellschaft der wissenschaften zu Göttingen. Philologisch-historische klasse. Neue folge, bd. VI. nro. 4. Weidmann, Berlin.

Szemiński, J. 2005. ¿Que significan "letras" en el libro segundo de "Nuevo Ophir" de Fernando de Montesinos? Anuario de Estudios Bolivianos, Archivísticos y Bibliográficos 11:585-598.

Timberlake, M. 2001. The Painted Image and the Fabrication of Colonial Andean History: Jesuit and Andean Visions in Conflict. Matrimonio de García de Loyola con Ñusta Beatriz. Ph.D. Dissertation, University of California, Los Angeles.

Trigo, D.E. y A. Korpisaari 2018. Los vasos con forma de calavera: símbolo de un ritual de decapitadores y elemento panandino. Arqueología Boliviana 4:189-213.

Wichrowska, O. y M. Ziółkowski (eds.) 2000. Iconografía de los keros. Andes. Boletín de la Misión Arqueológica Andina 5.

Ziółkowski, M. 1979. Acerca de algunas funciones de los keros y de los akillas en el Tawantinsuyu incaico y en el Perú colonial. Estudios Latinoamericanos 5:11-24.

Ziółkowski, M. 2000. Los keros del Museo Estatal de Etnografía de Varsovia. En Iconografía de los Keros, editado por O. Wichrowska y M. Ziółkowski, pp.123-139. Andes. Boletín de la Misión Arqueológica Andina no. 5.

Ziółkowski, M. 2009. Lo realista y lo abstracto: observaciones acerca del posible significado de algunos tocapus (t'uqapu) "figurativos". Estudios Latinoamericanos 29:307-334.

Ziółkowski, M. 2016. Del orden divino o ¿por qué eran obedecidos los soberanos de Vilcabamba? En Vilcabamba. Entre Arqueologia, Historia y Mito, editado por J.J. Decoster y M. Ziółkowski, pp. 184220. Centro Bartolomé de las Casas - Centro de Estudios Andinos de la Universidad de Varsovia en el Cusco - Centro Tinkuy, Cusco.

Ziólkowski, M. 2018. The Iconography and Use of Inca and Colonial Drinking Vessels. En The Oxford Handbook of the Incas, editado por S. Alconini y A. Covey, pp. 669-689. Oxford University Press, New York

Ziółkowski, M., J. Arabas y J. Szeminski, 2008. La historia en los queros: apuntes acerca de la relación entre las representaciones figurativas y los signos 'tocapus'. En Lenguajes Visuales de los Incas, editado por P. González Carvajal y T.L. Bray, pp. 163176. BAR International Series 1848, Oxford.

\section{Notas}

${ }^{1}$ Museum Am Rothenbaum. Kulturen und Künste der Welt (MARKK - a. Museum für Völkerkunde, Hamburg).

${ }^{2}$ Carta de la Dra. Christine Chávez, curadora de la colección americanista del MARKK del 21.06.2019.

${ }^{3}$ Para facilitar el análisis iconológico presentado a continuación se realizaron dibujos en blanco y negro asi como en color de todos los personajes. Estas figuras, acompañadas de descripciones sumarias, constituyen el Anexo 1 en este artículo.

${ }^{4}$ Según la lógica interna de la composición, el líder del grupo B debería encontrarse en la hilera superior, donde están representados los dos Incas.

${ }^{5}$ El tema de la relación entre las escenas figurativas en los queros (y otros soportes materiales) y las narraciones mito-históricas andinas está ampliamente debatidas en la literatura de la materia, mencionemos como ejemplo algunas referencias básicas: $\mathrm{De} \mathrm{La}$ Jara 1975; Chávez 1984; Cummins 1988, 2002, 2005; Flores et al. 1998; Jiménez 1994; Liebscher 1986a,1986b, 1986c; Mártinez
2010; Martínez y Martínez 2013; Mártinez et al. 2014; Posnansky 1931; Ramos, 2002, 2003, 2006; Rowe 1961, 2003; Szeminski 2005; Ziółkowski 1979, 2000, 2009, 2018; entre otros.

${ }^{6}$ En lo que toca el color de la piel y los rasgos faciales. En el caso de un objeto de una colección privada de nuestro conocimiento, los protagonistas europeos llevan un bigote. ${ }^{7}$ Se revela necesario en este momento presentar la posición que tomamos respecto a cierta categoría de queros denominados "queros de la transición". Son estos recipientes en forma de un cono truncado decorados con motivos geométricos y representaciones muy esquemáticas de rostros humanos o cabezas de animales. La decoración está realizada con incisiones en las paredes. Estos vasos están presentes en contextos funerarios prehispánicos, pero siguen produciendose en tiempos coloniales hasta inicios del siglo 17. Según algunos autores entre estos J. H. Rowe y M.A. Lizárraga, estos "vasos de transisión" son los vehículos de la decoración figurativa elaborada con la técnica 
de laca vegetal a inicios del periodo Colonial (Lizárraga 2009; Rowe 2003). La omisión en el presente texto de referencia a esta categoría particular de objetos no es casual, sino premeditada. En breve: según nuestra opinión los llamados "queros de transición" no representan un etapa en una evolución lineal de la decoración de los queros en tiempos coloniales, sino más bien una línea paralela a otra/s. Posiblemente esto se debe al uso particular de esta categoría de objetos, asociados aparentemente a ceremonias funerarias. En cambio, si aceptamos tanto los datos de los crónistas (Molina y Sarmiento de Gamboa) como la datación temprana (1538-1540) de la paqcha con el desfile militar (Cabello Caro 2006), esto supone la existencia de representaciones figurativo-narrativas en objetos de madera, por lo menos sincrónicos con los "queros de transición".

${ }^{8}$ Acerca de los programas ideológico-políticos de los Incas de Vilcabamba véase también Ziółkowski 2016.

${ }^{9}$ Las fechas son de $1593 \pm 35$ cal DC y de de $1558 \pm 35$ cal DC, respectivamente (Fonseca y Bauer 2015:104, 126-127, citado en Arzi et al. 2019:159).

${ }^{10}$ Este es un punto que se merece un discusión aparte, en particular en referencia a la edad atribuida a los queros en la obra magna de Jorge Flores Ochoa, Elisabeth Kuon Arce y Roberto Samanez Argumedo (Flores et al. 1998). Los autores de este valioso estudio atribuyen a la principal parte de los objetos analizados una cronologia tardía, es decir el siglo XVIII, sin hacer caso de las evidentes diferencias estilisticos-formales entre los numerosos objetos clasificados de esta manera y sin presentar argumentos tangibles en apoyo a esta cronología (p.ej., Flores et al. 1998:183, 186 y 187). Esta "cronología tardía" está también retomada en Martinez et al. 2014. Un caso bien ilustrativo de las serias contradicciones respecto a la cronología de los objetos de nuestro interés es la datación del conocido baúl (o cofre) de madera, con decoración policromada, de La Paz. Los autores de la mencionada obra lo clasifican como perteneciente al siglo XVIII (Flores et al. 1998:94-95) haciendo caso omiso de un detalle diagnóstico identificado por John H. Rowe: la forma de sombrero de copa alta típica del siglo XVI o comienzos del XVII (Rowe 2003 [1961]:316). En cambio, Teresa Gisbert situa el objeto en el siglo XVI, precisamente en base al estilo de la vestimenta de tres españoles representados en el objeto, que la autora identífica como "gola y sombrero a la moda de Felipe II" (Gisbert 2001:89).

${ }^{11}$ Se trata del estudio "Pescadores artesanos, y mercaderes costeños en el Perú prehispánico" (Rostworowski 1977:211-264).

${ }^{12}$ British Museum, Am 1909,0403.1 PRN: ESA9306. El objeto ha sido publicado de manera sumaria por Colin McEwan (2009:9293).

${ }^{13}$ Dimensions: Height: $13.00 \mathrm{~cm}$, Width: $70.50 \mathrm{~cm}$, Depth: $50.00 \mathrm{~cm}$, Weight: $40.00 \mathrm{~kg}$ (British Museum, Am1909,0403.1 PRN: ESA9306),

${ }^{14}$ Documento incluido en la crónica de Hernando de Santillán (1968 [1563]:101). Citado también por Marco Dorta (1975:68) y Rostworowski (1977:239-240).

${ }^{15}$ Carta del clérigo Juan de Vera al Consejo de Indias. Cuzco 9 de abril de 1572. A.G.I. Citada en Levillier 1956:66 y ss. Documento citado y comentado en un estudio anterior sobre este tema (Ziółkowski 2009:309).

${ }^{16}$ Thomas Cummins analizó la relación entre estos tres conjuntos de dibujos, llegando a la conclusión de que el más antiguo de estos es el contenido en el Manuscrito Galvin fechado en 1590. Sin embargo, el Estudioso observó que en la elaboración de la serie de retratos de Incas y Coyas de esta última obra contribuyeron al menos dos artistas distintos, además todos estos retratos proceden de una obra anterior de origen y fecha desconocida. Guaman Poma se hubiera basado en su serie de dibujos en el Manuscrito Galvin (Cummins 2005:20-21). Queda, sin embargo, establecer, ¿en qué momento de su vida y en base a qué tipo de enseñanza Guaman Poma adquirió la capacidad de dibujar? La tesis de que esto ocurrió en tiempos de su colaboración con Martín de Murúa, a inicios del siglo XVII, omite un detalle importante: por aquel entonces el cronista indio tenía como mínimo bien pasados los 50 años de edad, si no unos 70 (Adorno 2001), edad respetable, ya poco propicia para empezar a formarse como artista.

${ }^{17} \mathrm{Hubo}$ al parecer otras copias (de copias), hasta una de 1778 (Barnes 1996). Véase la discusión de este tema por Teresa Gisbert (1980:117 y ss). Acerca de otras formas de representar a la dinastía inca, en particular durante las procesiones, veáse el estudio de Karine Perissat (2000).

${ }^{18}$ Jiménez de la Espada 1879:XIX y ss. La carta de 1 de marzo de 1572 , con "La fe y testimonio que va puesta en los cuatro paños ...", fue publicada también por Jiménez de la Espada en el Apéndice en la edición de Fernando Montesinos: Memorias antiguas historiales y políticas del Perú. En Colección de Libros Españoles Taros y Curiosos, tomo XVI. Madrid, 1882, págs. 244 y ss., citado en Marco Dorta 1975:70

${ }^{19}$ Véase la nota anterior.

${ }^{20} \mathrm{El}$ tema de la guerra de los Incas con los Chancas ha sido debatido por varios autores. Entre los más recientes estudios notemos la monografía de Clementina Battcock en la que la Autora aborda el importante tema de las diferentes atribuciones de la victoria inca: a Viracocha Inca o a Pachacuti Inca Yupanqui (Battcock 2018). Otra aproximación, que en parte permitiría resolver la aparente contradicción en la atribuición de este mérito, es la de Amnon Nir (2016). Este estudioso plantea la hipótesis de que la versión "tradicional" de la guerra de los Incas con los Chancas es un resumen de siete contiendas esparcidas a lo lo largo de los reinados de como mínimo 3 soberanos incas. De toda maneras, el tema ocupaba un posición prominente en la tradición mito-histórica de los incas: “(...$)$ comenzando este cantar las señoras mujeres que detrás de ellos estaban, en el cual cantar decían e declaraban la venida que Uscovilca había venido sobre ellos e la salida de Viracocha Ynga e como Ynga Yupangue le había preso e muerto, diciendo que el Sol le había dado favor para ello como a su hijo, e como después, ansimismo, había desbaratado y preso e muerto a los capitanes que ansí habían hecho la junta postrera" (Betanzos 1987 (1551) I p. cap. XIII: 61).

${ }^{21}$ El muy debatido tema de la "cabeza-trofeo"y sus representaciones, como símbolo de victoria, ha sido recientemente resumido en un estudio de David E. Trigo Rodríguez y Antti Korpisaari (2018). La decapitación del adversario podía ocurrir en el mismo campo de batalla, pero también en actos posteriores a la contienda misma. Sarmiento de Gamboa afirma, por ejemplo, que a Chuchi Capac, señor de los Collas, vencido por Pachacuti Inca Yupanqui, se lo ha decapitado, pero no en el campo de batalla, sino en el Cusco, después de la ceremonia del triumfo en la que actuó el mismo Chuchi Capac en calidad de preso (Sarmiento de Gamboa 1906 [1572]: cap. 37:76). Vale la pena recordar a la cabeza de Atoc, usada como vaso por Atahuallpa, Betanzos menciona también actos similares realizados, uno por Huascar en la persona del emisario de Atahuallpa (Betanzos 1987 [1551]: II p., cap. II:210) y otro por Atahuallpa en la persona del emisario que le llevó una información decepcionante acerca del comportamiento de los españoles en Cajamarca (Betanzos 1987 [1551]: II p., cap. XXIII:276). Pero estos últimos contextos no están directamente asociados a los actos ocurridos en un campo de batalla o consecuencia de la misma.

${ }^{22}$ Encontramos este dato en la descripción del regreso de Huayna Capac de su campaña victoriosa contra los Chachapoyas. Por razones ceremoniales asociados al luto por la muerte de su madre, el soberano prohibió a sus soldados pintarse con rojo y de manifestar cualquier señal de triunfo: "mandó a los suyos que ninguno fuese osado a se pintar la cara de colorado, ni ponerse otra color en él, si no fuese de la que el Ynga llevaba puesta, que era negra por luto (...)" (Betanzos 1987 [1551]: I parte, cap. XLIV:190). Esta costumbre de pintarse la cara en rojo tenía su nombre específico: Llimppicuni, pintarse con bermellon la cara y embijarse (Gonçalez Holguin 1608:153). 
Anexo 1. Dibujos y descripción de los personajes representados en el quero del Museum für Völkerkunde, Hamburgo.
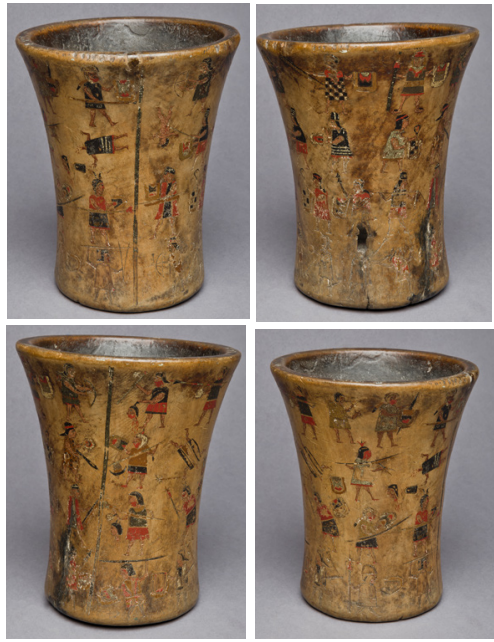

Fotos de los cuatro lados del q'ero de Hamburgo (fotos Paul Schimweg, cortesía del Museum Am Rothenbaum. Kulturen und Künste der Welt, Hamburgo).

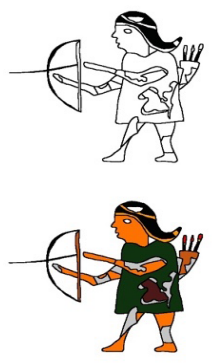

GRUPO: A

Subgrupo de los guerreros: Chunchus

Código: AI1

Atributos: arco y flechas

Ubicación: ubicación prominente en el registro superior, a la izquierda de los Incas.

Descripción: figura de un guerrero representado de perfil, mirando hacia la izquierda, vestido con una túnica verde, lleva un arco en sus manos y un carcaj con flechas en la espalda; una cinta (¿tejida?) en la cabeza.

Conexiones: el personaje parece representar a los moradores del Antisuyu.

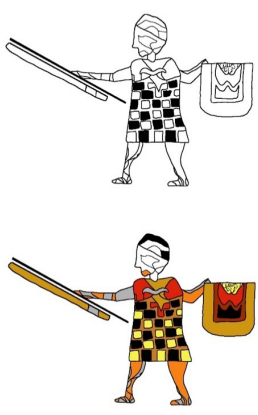

GRUPO: A

Subgrupo: Incas

Código: AI2

Atributos: escudo conocido de otros queros como identificadores de soberanos y/o militares de alto rango.

Ubicación: ubicación prominente en el registro superior, en el medio, al lado del otro Inca.

Descripción: figura de un miembro de la élite Inca, representado frontalmente con la cabeza vuelta hacia la izquierda; vestido con un uncu a cuadros multicolor (negroamarilllo), un diseño similar a una tabla de ajedrez; con accesorios rojos y una pechera, lleva un escudo en la mano izquierda y una lanza corta, decorada con una tipo de banda o cinta de color amarillo en su mano derecha.

Conexiones: Probablemente la capital, Cusco. 


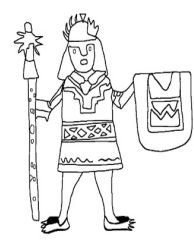

GRUPO: A

Subgrupo: Incas

Código: AI3

Atributos: escudo conocido de otros queros como identificadores de soberanos y/o militares de alto rango y un tupayauri o tipo de lanza.

Ubicación: ubicación prominente, en el registro superior, en el medio, al lado del otro Inca.

Descripción: figura de un miembro de la élite Inca, representado frontalmente en face; vestido con un uncu de color verde con un cinturón dorado (amarillo), una pechera y con aplicaciones rojas; lleva un escudo en su mano izquierda y un tupayauri con cabeza en forma de estrella en su mano derecha; calza sandalias (único entre los personajes representados, quizás aparte del B II3), en la cabeza lleva un helmete rojo.

Conexiones: Probablemente la capital Cusco.

\section{GRUPO: A}

Subgrupo de los guerreros: Chunchus

Código: AI4

Atributos: arco, flechas y carcaj.

Ubicación: ubicación prominente, en el registro superior, a la derecha de los Incas.

Descripción: figura de un guerrero representado de perfil, mirando hacia la derecha; vestido con una túnica verde con decoración en forma de banda de rombos (amarillo, rojo); lleva un arco en sus manos y un carcaj con flechas en la espalda; una o dos cinta/s (¿tejida?) en la cabeza.

Conexiones: el personaje parece representar a los moradores del Antisuyu.

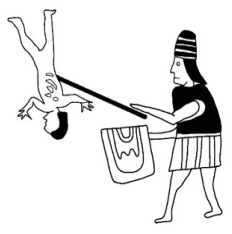

\section{GRUPO: A}

Subgrupo de los guerreros: Collas

Código: AII1-AII2

Atributos: el tipo de chucu o helmete y un escudo.

Ubicación: en el segundo registro (contando desde arriba).

Descripción: -AII1-, un personaje desnudo yacente, apuntado (¿picado?) con la lanza de un soldado, carece de elementos que permitan su identificación étnico/social, salvo

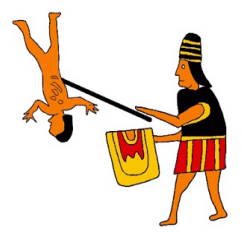
el cabello aparentemente tresquilado. Su adversario -AII2-; representado del perfil con la cabeza vuelta hacia la izquierda; vestido con un uncu negro-rojo con rayas verticales amarillas en la parte inferior; lleva un escudo en la mano derecha y una lanza en la mano izquierda; en su cabeza hay un tipo de chucu o helmete. La forma característica del helmete permiten identificarlo como Colla.

Conexiones: el personaje parece representar a los moradores del Collasuyu. 

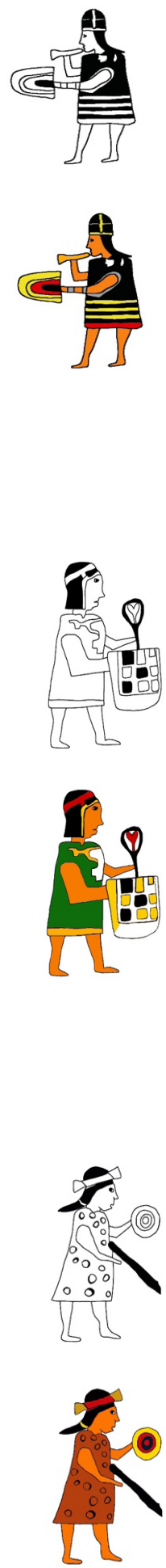

Grupo: A

Subgrupo de los guerreros:

Código: AII3

Atributos: trompeta y escudo.

Ubicación: en el segundo registro, en el medio, debajo del Inca.

Descripción: individuo representado de perfil, volteado hacia la izquierda; toca un tipo de trompeta, esta es probablemente una quepa o bocina elaborada con un calabazo. El personaje viste una túnica negra con rayas horizontales amarillas y rojas en la parte inferior; lleva un escudo en la mano izquierda; en su cabeza hay un tipo de chucu o helmete; la forma característica del helmete permiten identificarlo como Colla. Conexiones: el personaje parece representar a los moradores del Collasuyu.

\section{GRUPO: A}

Subgrupo de los guerreros:

Código: AII4

Atributos: un escudo con un diseño similar a una tabla de ajedrez y arma no identificada. Ubicación: en la segunda hilera.

Descripción: individuo representado de perfil, volteado hacia la derecha; vestido con una túnica verde con aplicaciones amarillas; en la mano derecha lleva un escudo con un diseño similar a una tabla de ajedrez y un arma (¿porra?) en en la izquierda; un tipo de cinta de color rojo en la cabeza;

Conexiones: pertenece al mismo grupo de guerreros que el personaje AIII2. Afiliación étnica exacta indeterminada.

\section{GRUPO: A}

Subgrupo de los guerreros:

\section{Código: AII5}

Atributos: un escudo redondo

Ubicación: en la seguna hilera

Descripción: un guerrero representado de perfil, mirando hacia la derecha; vestido con una túnica marrón con manchas (¿alusión a la piel de jaguar?); lleva un escudo redondo en la mano izquierda y un tipo de porra en la derecha; una cinta de color rojo con dos aplicaciones amarillas en la cabeza.

Conexiones: Afiliación étnica exacta indeterminada. 

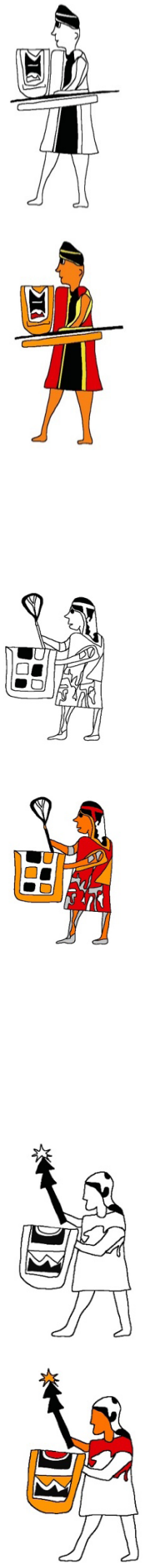

GRUPO: A

Subgrupo de los guerreros:

Código: AIII1

Atributos: uncu, tocado y lanza corta.

Ubicación: en la tercera hilera, cerca de la línea divisoria vertical.

Descripción: personaje representado de perfil, volteado hacia la izquierda; vestido con un uncu rojo con una banda negra vertical bordeada de rayas amarillas verticales en la parte central; lleva un escudo en la mano derecha y en la izquierda una lanza corta, decorada con una tipo de banda o cinta de color amarillo; en su cabeza hay un tipo de gorro de color negro con dos elementos lineales amarillos.

Conexiones: pertenece al mismo grupo de guerreros que el personaje AIII5. Afiliación étnica exacta indeterminada.

\section{GRUPO: A}

Subgrupo de los guerreros:

Código: AIII2

Atributos: un escudo con un diseño similar a una tabla de ajedrez y un tipo de arma. Ubicación: en la tercera hilera.

Descripción: individuo representado de perfil, volteado hacia la izquierda; vestido con una túnica roja con aplicaciones amarillas; en la mano izquierda lleva un escudo con un diseño similar a una tabla de ajedrez y un arma (iporra?) en la derecha; una cinta de color rojo en la cabeza.

Conexiones: pertenece al mismo grupo de guerreros que el personaje AII4. Afiliación étnica exacta indeterminada.

\section{GRUPO: A}

Subgrupo de los guerreros:

Código: AIII3

Atributos: escudo y una porra

Ubicación: en la tercera hilera, en el medio.

Descripción: guerrero representado de perfil, volteado hacia la izquierda; vestido con una túnica roja; en la mano izquierda lleva un escudo con diseño parecido a los de los Incas (AI2 y AI3) y una porra con cabeza en forma de estrella.

Conexiones: pertenece al mismo grupo de guerreros que el personaje AIV5 (tienen el mismo tipo de arma). Por la similitud de escudos (AI2 y AI3) podría pertenecer a los Incas. 

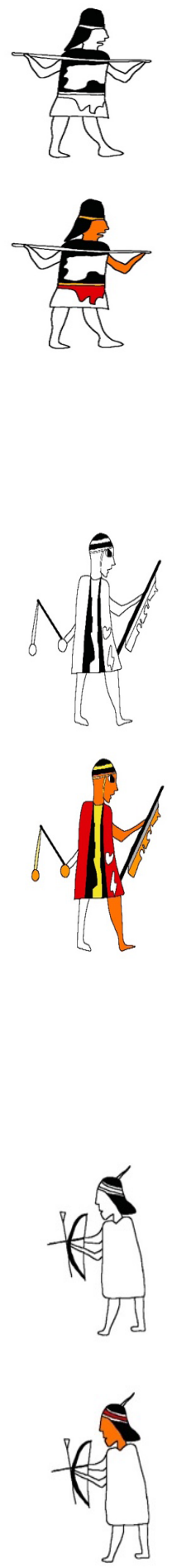

GRUPO: A

Subgrupo de los guerreros: Collas

Código: AIII4

Atributos: el tipo de chucu o helmete, lanza.

Ubicación: en la tercera hilera.

Descripción: personaje representado de perfil con la cabeza volteada hacia la derecha; vestido con un uncu negro-rojo con un cinturón amarillo; llava una arma en sus manos, probablemente un tipo de lanza; en su cabeza hay un tipo de chucu o helmete. Conexiones: a juzgar por la forma del helmete, probalemente representa a un Colla.

GRUPO: A

Subgrupo de los guerreros:

Código: AIII5

Atributos: uncu, tocado y arma.

Ubicación: en la tercera hilera, cerca de la línea divisoria vertical.

Descripción: personaje representado de perfil, volteado hacia la derecha; vestido con un uncu rojo con una banda negra vertical; lleva dos armas, un tipo de maza en la mano derecha y en la izquierda una lanza corta, decorada con una faja o cinta de color amarillo; en su cabeza gorro de color negro decorado con una raya horizontal amarilla.

Conexiones: pertenece al mismo grupo de guerreros que el personaje AIII1. No identificado a nivel étnico.

GRUPO: A

Subgrupo de los guerreros: Chunchus

Código: AIV1

Atributos: arco y flechas

Ubicación: en el registro inferior a la izquierda.

Descripción: un guerrero representado de perfil, mirando hacia la izquierda; vestido con una túnica; lleva un arco con una flecha en sus manos; una cinta roja la cabeza. Conexiones: el personaje parece representar a los moradores del Antisuyu. 

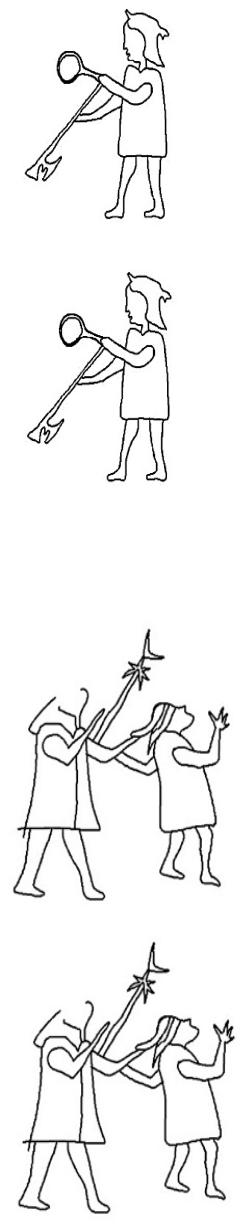

GRUPO: A

Subgrupo de los guerreros: no se puede identificar con certitud a causa del mal estado de conservación de la laca incrustada.

Código: AIV2

Atributos: una hacha en la mano derecha y un objeto no identificado en la izquierda, posiblemente un arma parecida a la de los personajes AIII2 y AII4.

Ubicación: en el registro inferior.

Descripción: figura de un guerrero representado de perfil, mirando hacia la izquierda; vestido con una túnica; lleva una hacha y un objeto no identificado en las manos. Tiene el cabello largo.

Conexiones: No identificado a nivel étnico.

GRUPO: A

Subgrupo de los guerreros: no se puede identificar con certitud a causa del mal estado de conservación de la laca incrustada.

Código: AIV3-AIV4

Atributos: porra y prisionero

Ubicación: en el registro inferior, cerca de la línea divisoria vertical.

Descripción: AIV3 - figura de un guerrero representado de perfil, mirando hacia la derecha; vestido con una túnica; lleva una porra con la cabeza en forma de estrella en la mano derecha; con la izquiertda agarra por el cabello el personaje AIV4 - este está vestido y de pie, pero desarmado; representado de perfil, mirando hacia la derecha. Conexiones: La escena parece representar al acto de captura/sumisión en campo de batalla. No se puede identificar a nivel étnico a los protagonistas.

GRUPO: A

Subgrupo de los guerreros: El mal estado de conservación de la laca incrustada dificulta una descripción precisa.

Código: AIV5

Atributos: escudo y una porra con cabeza en forma de estrella.

Ubicación: en la cuarta hilera, cerca de la línea divisoria vertical.

Descripción: guerrero representado de perfil, mirando hacia la derecha, cabello largo; vestido con una túnica roja; lleva un escudo en la mano derecha y la porra en la izquierda.

Conexiones: pertenece al mismo grupo de guerreros que el personaje AIII3 (tienen el mismo tipo de arma). No identificado a nivel étnico. 

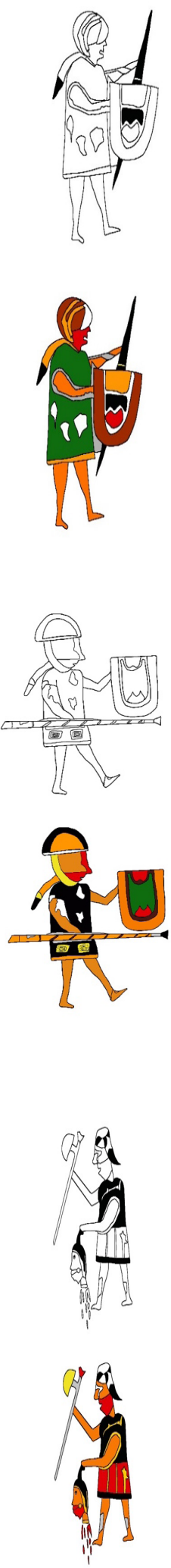

GRUPO: B

Subgrupo de los guerreros:

Código: BI1

Atributos: un tocado en forma de un helmete provisto de una "trenza", escudo y arma.

Ubicación: en la primera hilera, a la izquierda.

Descripción: guerrero representado de perfil, mirando hacia la derecha posiblemente; pintura facial de color rojo; vestido con una túnica verde con aplicaciones amarillas; lleva un escudo en la mano derecha y un arma (iporra?) en la izquierda; lleva en la cabeza un tipo de helmete provisto de una "trenza" (o ¿cola?).

Conexiones: pertenece al mismo grupo de guerreros que los personajes: BI2, BII3 y BIII1. A juzgar por la posición en la hilera superior, la misma que los Incas del Grupo A, se trata de un integrante de los principales adversarios de estos últimos. ¿Chanca?

\section{GRUPO: B}

Subgrupo de los guerreros:

Código: $\mathrm{BI} 2$

Atributos: helmete provisto de una "trenza", escudo y lanza.

Ubicación: en la primera hilera, cerca a la línea divisoria vertical.

Descripción: guerrero representado de perfil, mirando hacia la derecha posiblemente; pintura facial de color rojo; vestido con un uncu negro con aplicaciónes amarillas; lleva un escudo en la mano izquierda y una lanza corta en la derecha; vestido con un uncu negro con aplicaciónes amarillas; lleva en la cabeza un tipo de helmete provisto de una "trenza" (o ¿cola?).

Conexiones: pertenece al mismo grupo de guerreros que los personajes: BI1, BII3 y BIII1. ¿Chanca?

\section{GRUPO: B}

Subgrupo de los guerreros:

Código: BI3;

Atributos: un tipo de arma, hacha, cabeza trofeo.

Ubicación: en la primera hilera del lado derecho, cerca a la linea divisoria vertical. Descripción: un guerrero representado de perfil, mirando hacia la izquierda; pintura facial de color rojo; vestido con un uncu negro-rojo con rayas verticales amarillas en la parte inferior; lleva una hacha en la mano derecha y una cabeza trofeo en la izquierda (la pintura facial del guerrero en cuestión y la de la cabeza cortada son idénticas).

Conexiones: este personaje tiene el mismo tipo de uncu que usa el personaje AII2. Afiliación étnica indtereminada. 

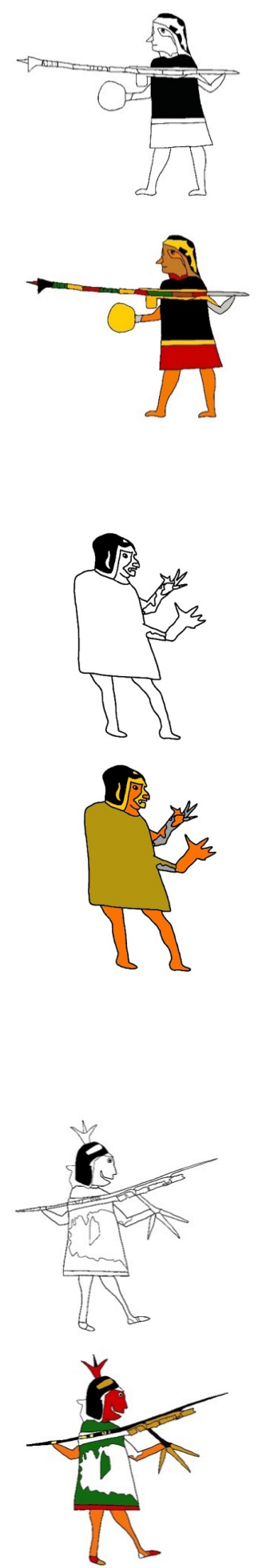

GRUPO: B

Subgrupo de los guerreros:

Código: BI4

Atributos: un tipo de uncu negro-rojo; un escudo redondo y un arma.

Ubicación: en la primera hilera, a la derecha.

Descripción: un guerrero representado de perfil, mirando hacia la izquierda; pintura facial de color rojo; vestido con un uncu negro-rojo con aplicaciónes amarillas; sostiene un escudo redondo y (probablemente) una estólica o una lanza.

Conexiones: este personaje tiene el mismo tipo de uncu que usa el personaje BIII3. Afiliación étnica exacta no determinada.

\section{GRUPO: B}

Subgrupo de los guerreros:

Código: BI5

Atributos: dedos con garras (i?)

Ubicación: en la hilera superior, a la derecha.

Descripción: un personaje representado de perfil, mirando hacia la derecha; vestido con una túnica verde; puesto aparte al preso (AIV4) y el victimado (AII1) el único protagonista de la contienda desprovisto de cualquier arma. Sin embargo, sus manos estan representadas de manera particular, parecen garras; es también notable la representación de su rostro: boca abierta, en la que se nota algo como un colmillo puntiagudo.

Conexiones: Tiene que ser un protagonista importante a juzgar por su ubicación en el registro superior. Por la presencia de "garras" y la forma de boca, podría tratarse de un ser no-humano (¿huaca?).

\section{GRUPO: B}

Subgrupo de los guerreros:

Código: BII1

Atributos: tocado en forma de tres elementos verticales encima de la cabellera.

Ubicación: en la segunda hilera, a la izquierda.

Descripción: un guerrero representado de perfil, mirando hacia la derecha; pintura facial de color rojo cunbre integralmente el rostro; vestido con un uncu verde con aplicaciónes rojas; lleva un arma en la mano derecha, probablemente una estólica o lanza; en la mano izquierda un objeto compuesto de una manga y tres elementos puntiagudo, lleva un tocado en forma de tres elementos verticales encima de la cabellera.

Conexiones: Afiliación étnica indeterminada. 

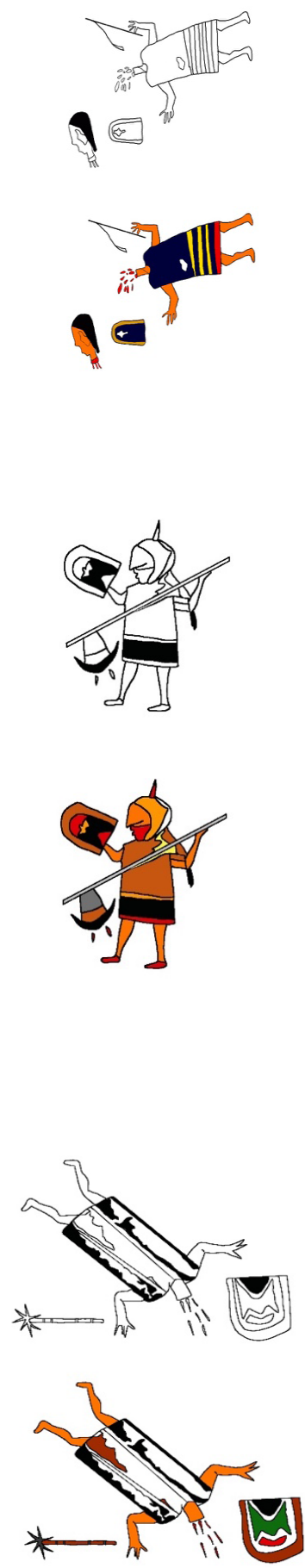

GRUPO: B

Subgrupo de los guerreros:

Código: BII2

Atributos: maza, escudo

Ubicación: en la segunda hilera, cerca a la línea divisoria vertical.

Descripción: cuerpo decapitado yacente de un guerrero; vestido con un uncu azul-marino con bandas horizontales amarillas y rojas; cerca del cuerpo yacen una maza, un escudo y la cabeza cercenada.

Conexiones: Identificación étnica indeterminada.

GRUPO: B

Subgrupo de los guerreros:

Código: BII3

Atributos: un tocado en forma de un helmete provisto de una "trenza", escudo y arma.

Ubicación: en la segunda hilera, cerca a la línea divisoria vertical.

Descripción: figura de un guerrero representado de perfil, mirando hacia la izquierda; pintura facial de color rojo; vestido con un uncu marrón-negro con aplicaciónes amarillas y rojas; lleva un escudo en la mano derecha y una hacha (i?) en la izquierda; el personaje lleva un helmete provisto de una "trenza" ( 0 cola?); un detalle interesante: tiene los pies pintados en rojo o bien es esta la representación de algún tipo de calzado.

Conexiones: pertenece al mismo grupo de guerreros que los personajes: BI1, BI2 y BIII1.¿Chanca?

\section{GRUPO: B}

Subgrupo de los guerreros:

Código: BII4

Atributos: porra con cabeza estrellada y un escudo.

Ubicación: en la segunda hilera, a la derecha.

Descripción: cuerpo decapitado; vestido con un uncu azul-marino-marrón con bandas verticales; la porra y el escudo yacen al lado; la cabeza esta ausente puede ser la llevada por el personaje BI3 o por el BIII3.

Conexiones: La decoración de la túnica (banda vertical ancha) y el tipo de escudo son semejantes a las del personaje AIII1. Afiliación étnica indeterminada. 

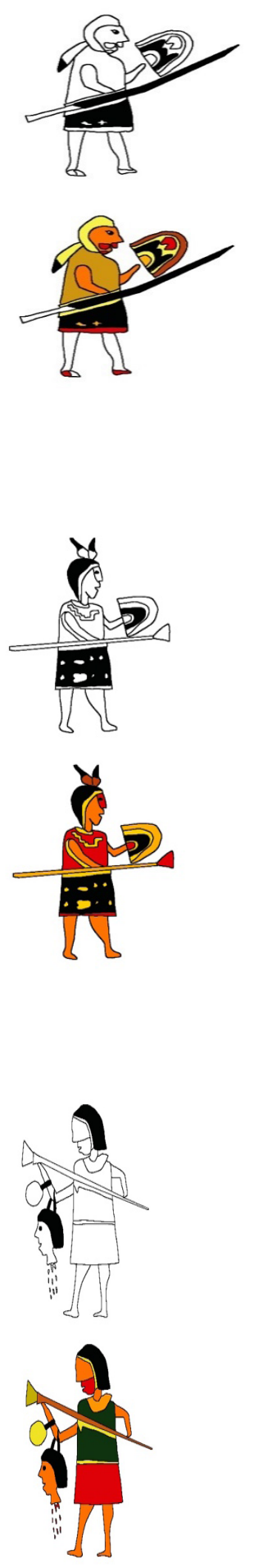

GRUPO: B

Subgrupo de los guerreros:

Código: BIII1

Atributos: un tocado en forma de un helmete provisto de una "trenza", escudo y lanza.

Ubicación: en la tercera hilera, a la izquierda.

Descripción: un guerrero representado de perfil, mirando hacia la derecha; pintura facial de color rojo; vestido con un uncu verde-negro con aplicaciónes rojas; lleva un escudo en la mano izquierda y una lanza en la derecha; lleva en la cabeza un tipo de helmete provisto de una "trenza" (o ¿cola?).

Conexiones: pertenece al mismo grupo de guerreros que los personajes: BI1, BI2 y BII3. ¿Chanca?

\section{GRUPO: B}

Subgrupo de los guerreros:

Código: BIII2

Atributos: un tocado en forma de dos elementos verticales encima de la cabellera, escudo y una lanza.

Ubicación: en la tercera hilera, cerca a la linea divisoria vertical.

Descripción: un guerrero representado de perfil, mirando hacia la derecha; pintura facial de color rojo; vestido con un uncu rojo-negro con aplicaciones rojas y amarillas; lleva un escudo en la mano izquierda y una lanza en la derecha; lleva también un particular tipo de tocado en forma de dos elementos verticales, parecidos a alas, encima de la cabellera, Conexiones: por la forma de tocado se asemeja al personaje BIII4.

\section{GRUPO: B}

Subgrupo de los guerreros:

Código: BIII3

Atributos: un escudo (¿?) redondo y una lanza, una cabeza cercenada.

Ubicación: en la tercera hilera, cerca de la línea divisoria vertical.

Descripción: un guerrero representado de perfil, mirando hacia la izquierda; pintura facial de color rojo; vestido con un uncu negro-rojo con aplicaciones amarillas; lleva una lanza en la mano izquierda; la cabeza del trofeo de un adversario y un elemento redondo (¿escudo?) están colgados en su mano derecha.

Conexiones: se asemeja al personaje BI4 por el tipo de uncu y el elemento redondo (¿escudo?). Afiliación étnica indeterminada. 


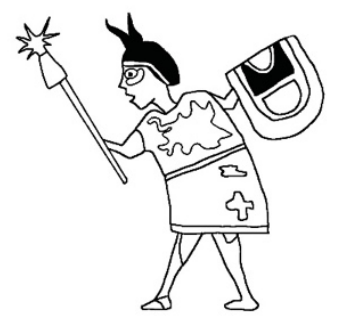

GRUPO: B

Subgrupo de los guerreros:

Código: BIII4

Atributos: particular tipo de tocado en forma de dos elementos verticales encima de la cabellera, escudo y un tipo de arma.

Ubicación: en la tercera hilera, a la derecha.

Descripción: un guerrero representado de perfil, mirando hacia la izquierda; pintura facial de color rojo; vestido con un uncu rojo-negro con aplicaciones rojas

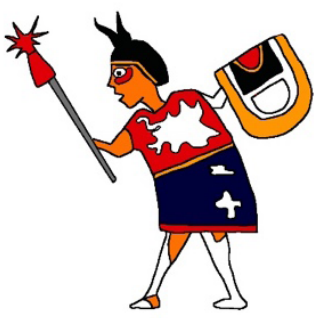
y amarillas; lleva un escudo en la mano izquierda y una porra con cabeza en forma de estrella en la derecha; lleva también un particular tipo de tocado en forma de dos elementos verticales, parecidos a alas, encima de la cabellera.

Conexiones: por la forma de tocado y el diseño del uncu se asemeja al personaje BIII2. Afiliación étnica indeterminada.

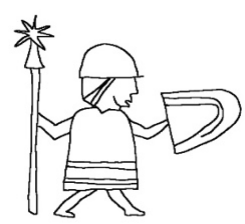

\section{GRUPO: B}

Subgrupo de los guerreros: no se puede identificar con certitud a causa del mal estado de conservación de la laca incrustada.

Código: BIV1

Atributos: lanza con una cabeza estrellada, helmete y escudo.

Ubicación: en la hilera inferior, a la izquierda.

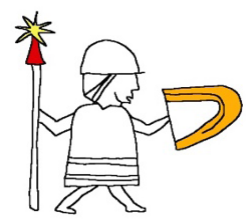

Descripción: un guerrero representado de perfil, mirando hacia la derecha; en la cabeza lleva un tipo de casco; vestido con un uncu; lleva un escudo en la mano izquierda y lanza en la derecha.

Conexiones: tiene el mismo tipo de arma que el personaje AI3. Afiliación étnica indeterminada.

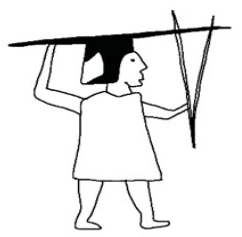

\section{GRUPO: B}

Subgrupo de los guerreros: no se puede identificar con exactitud por el mal estado de conservación de la laca incrustada.

Código: BIV2

Atributos: una lanza (?).

Ubicación: en la hilera inferior.

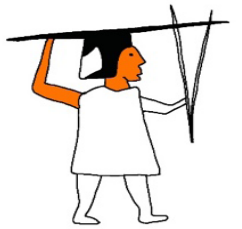

Descripción: un guerrero representado de perfil, mirando hacia la derecha; vestido con un uncu; lleva probablemente lanza (i?) en la mano derecha y un objeto de dos ramas ( $i$ ?) en la mano izquierda.

Conexiones: Afiliación étnica indeterminada. 

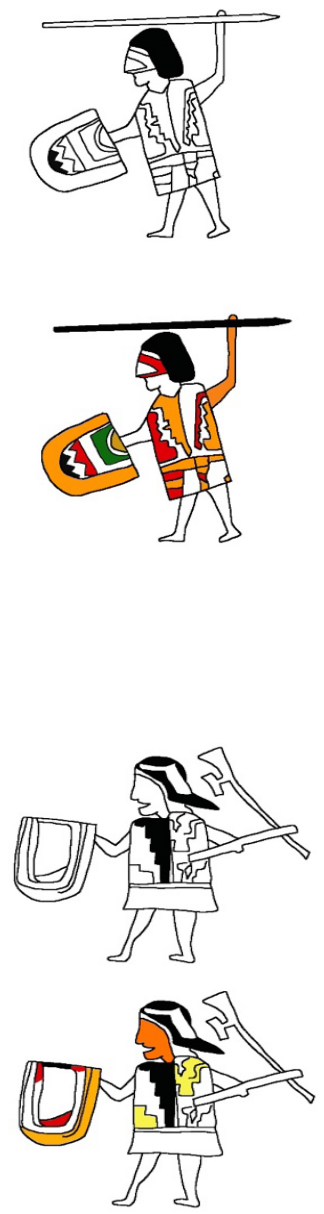

GRUPO: B;

Subgrupo de los guerreros: ¿Incas?

Código: BIV3

Atributos: un escudo una lanza o porra, un escudo.

Ubicación: en la hilera inferior.

Descripción: un guerrero representado del perfil con la cabeza vuelta hacia la izquierda; pintura facial de color rojo, vestido con un uncu rojo-amarillo decorado con un motivo escalonado; lleva un escudo en la mano derecha y un arma (¿lanza o porra?) en la izquierda.

Conexiones: se asemeja al personaje BIV4; a juzgar por el tipo de escudo y los motivos en su túnica, puede ser identificado como inca.

\section{GRUPO: B}

Subgrupo de los guerreros: ¿Incas?

Código: BIV4

Atributos: escudo y hacha

Ubicación: en la hilera inferior

Descripción: un guerreo, representado de perfil con la cabeza vuelta hacia la izquierda; vestido con un uncu negro-amarillo decorado de motivos escalonados; lleva un escudo en la mano derecha y una hacha en la izquierda.

Conexiones: se asemeja al personaje BIV3 por los motivos en el uncu. A juzgar por los motivos en su túnica y tipo de escudo, puede ser identificado tentativamente como inca. 